NBER WORKING PAPER SERIES

\title{
HOW TAXING IS TAX FILING? USING REVEALED PREFERENCES TO ESTIMATE COMPLIANCE COSTS.
}

\author{
Youssef Benzarti \\ Working Paper 23903 \\ http://www.nber.org/papers/w23903 \\ NATIONAL BUREAU OF ECONOMIC RESEARCH \\ 1050 Massachusetts Avenue \\ Cambridge, MA 02138 \\ October 2017
}

I thank Alan Auerbach, Stefano DellaVigna, Matthew Rabin and Emmanuel Saez for invaluable advice, guidance, and encouragement throughout this project. I benefited from discussions with Miguel Almunia, Pierre Bachas, Dan Benjamin, Kimberly Clausing, Erik Eyster, Alex Gelber, Daniel Gross, Ben Handel, Nathaniel Hendren, Hilary Hoynes, Emiliano Huet-Vaughn, Damon Jones, Louis Kaplow, Marc Kaufmann, Henrik Kleven, Wojciech Kopczuk, Laurence Kotlikoff, David Laibson, Etienne Lehmann, Attila Lindner, Adriana Lleras-Muney, Takeshi Murooka, Michaela Pagel, Colin Raymond, Alex Rees-Jones, Antonio Rosato, Jesse Rothstein, Josh Schwartzstein, Dan Silverman, Joel Slemrod, Charles Sprenger, Justin Sydnor, Alisa Tazhitdinova, Danny Yagan and seminar participants at the Tax Systems Conference (Oxford and U. of Michigan), Paris II, CREST, Aarhus University, SITE Psychology and Economics, the US Department of Treasury, Princeton, Harvard KSG, UCLA, McMaster, U. Mass Amherst and U. of Toronto. Funding from the Robert D. Burch Center for Tax Policy and Public Finance is gratefully acknowledged. The views expressed herein are those of the author and do not necessarily reflect the views of the National Bureau of Economic Research.

NBER working papers are circulated for discussion and comment purposes. They have not been peer-reviewed or been subject to the review by the NBER Board of Directors that accompanies official NBER publications.

(C) 2017 by Youssef Benzarti. All rights reserved. Short sections of text, not to exceed two paragraphs, may be quoted without explicit permission provided that full credit, including () notice, is given to the source. 
How Taxing Is Tax Filing? Using Revealed Preferences to Estimate Compliance Costs.

Youssef Benzarti

NBER Working Paper No. 23903

October 2017

JEL No. H24,H31,H83

\section{$\underline{\text { ABSTRACT }}$}

This paper uses a quasi-experimental design and a novel identification strategy to estimate the cost of filing income taxes. First, using US income tax returns, I observe how taxpayers choose between itemizing deductions and claiming the standard deduction. Taxpayers forgo tax savings to avoid compliance costs, which provides a revealed preference estimate of the compliance cost of itemizing. I find that this cost increases with income, consistent with a higher opportunity cost of time for richer house-holds. Second, using my estimates and estimates of the time required to file other schedules, I estimate the cost of filing federal income taxes. I find that this cost has been increasing since the 1980's and has reached 1.2\% of GDP in the most recent years.

Youssef Benzarti

Department of Economics

University of California, Los Angeles

Bunche Hall, 315 Portola Plaza

Los Angeles, CA 90095

and NBER

benzarti@econ.ucla.edu 
Income taxes represent the largest source of tax revenue in the United States. Today, $8.8 \%$ of GDP is transferred from individuals to the Federal Government through income taxes. While there is an extensive literature documenting the efficiency cost of taxation, we know less about the cost of collecting taxes. But every year, 140 million taxpayers spend numerous hours gathering receipts and statements, filling out various tax schedules and forms and submitting them to the Internal Revenue Service (I.R.S.). A large literature documents that individuals frequently leave "money on the table" in other domains because of transactional costs which would suggest that the compliance costs of taxation are likely to be very large. ${ }^{1}$

This paper provides the first estimate of this cost using quasi-experimental methods. I exploit the fact that taxpayers can choose between itemizing their tax deductions or claiming the standard deduction. Itemizing deductions requires some effort cost but can provide large tax savings. Claiming the standard deduction saves time and effort but results in more taxes due.

If compliance costs are non-existent, taxpayers should itemize if the benefit of itemizing is greater than zero. With compliance costs, itemizing is only beneficial if it reduces the tax bill by more than the cost of itemizing. This implies that if compliance costs are non-zero, some taxpayers will claim the standard deduction even though the sum of their deductions is greater than the standard deduction amount. The main identification challenge is to differentiate individuals who fail to itemize deductions because of compliance costs from individuals who claim the standard deduction because their total deductions are smaller than the standard deduction amount. This is particularly difficult because taxpayers who claim the standard deduction are not required to report their deductions, implying that their true level of deductions is not observable in tax data.

If individuals are forgoing tax benefits because of compliance costs, there should be a missing mass in the density of deductions just above the standard deduction threshold. I test this hypothesis by graphing the density of deductions for years ranging from 1980 to 2006 using a stratified random sample of US tax returns, weighted to be representative of the population of itemizers. The shape

\footnotetext{
${ }^{1}$ See for example Currie (2006), Bertrand et al. (2006) and more recently Bhargava and Manoli (2015).
} 
of the density function suggests the presence of a missing mass just above the standard deduction. To confirm that this shape is due to taxpayers responding to the standard deduction, I turn to a quasi-experimental design. Following a large increase in the standard deduction amount, I observe a drop in the mass of itemizers just above the post-reform standard deduction threshold. The postreform density is systematically lower than the pre-reform one just above the post-reform standard deduction threshold and the two densities overlap further away from the standard deduction. I ensure that no other reforms are affecting the densities of itemized deductions. ${ }^{2}$

I use the missing mass to construct the distribution of forgone benefits. I find significant heterogeneity among taxpayers. Some taxpayers still itemize even when savings are modest and some forgo large tax benefits, resulting in a large average cost of itemizing.

If individuals switch to the standard deduction because they value their time more than the benefits they can derive from itemizing, richer households should forgo more tax benefits than poorer ones. To test this hypothesis, I break down individuals by income deciles and repeat the estimation using the same identification strategy outlined above. The results show an increasing relationship between forgone tax benefits and income - while controlling for the marginal tax rate - consistent with the hypothesis that tax filing imposes a higher cost on richer individuals because they have a higher marginal value of time.

The presence of a missing mass just above the standard deduction is consistent with taxpayers forgoing benefits to avoid the cost of itemizing. However, there are three alternative explanations to the presence of the missing mass. The first is that the standard deduction acts a concave kink point, effectively changing the price of a deduction. Behavioral responses to concave kink points predict that taxpayers will respond to variations in marginal tax rates but should not respond to variations in income while holding the marginal tax rate fixed. The fact that forgone benefits increase with income - while controlling for the marginal tax rate - supports the compliance costs explanation. A second alternative explanation for the presence of a missing mass is that some taxpayers mistakenly believe that

\footnotetext{
${ }^{2}$ My estimates are not affected by the Alternative Minimum Tax, variation in marginal tax rates and the phase out of the personal interest deduction in 1987.
} 
Internal Revenue Service (IRS) audits are more likely when itemizing and switch to the standard deduction to avoid the expected cost of an audit. To assess this explanation, I conduct a survey of taxpayers to elicit their beliefs over audit probabilities and audit costs. I find that the perceived expected cost of audits would explain at most one fifth of the cost. A third alternative explanation is that the uncertainty taxpayers face over the amount of deductions they can claim drives them to not itemize. The cost I estimate is derived using taxpayers who were itemizing the year before the reform and deductions are stable over time, which implies that taxpayers should have a small uncertainty range over their level of total deductions. I show that for this theory to explain the result, this uncertainty range would need to be extremely large $( \pm \$ 14,000)$.

Next, I use the cost of itemizing to estimate the total cost of filing Federal income taxes. ${ }^{3}$ I find that total filing costs are significantly larger than previously estimated using surveys and this cost has been steadily increasing and reached more than $\$ 200$ billion $(\simeq 1.2 \%$ of GDP) in recent years. This increase has occurred in spite of the rise in the number of electronic filers over time. It can be explained by growth in the total number of filers - which has been faster than growth of the US population - and an increase in the number of additional schedules taxpayers have to file along with their 1040 form. To estimate total costs, I proceed in the following way. First, I use the population of itemizers just above the standard deduction to estimate key demographics likely to affect the cost of filing: income, use of tax preparers, electronic filing and dependents. With these estimates, I can impute the cost of itemizing for non marginal itemizers. Second, I use IRS survey estimates of the number of hours required to file each tax schedule to infer the cost of filing other schedules from the cost of itemizing. My approach relies on three key assumptions. The first is that controlling for the demographics I estimate, the cost of filing for individuals just above the standard deduction is similar for other filers. The second is that controlling for the number of hours required to file a schedule, individuals do not dislike filing a given schedule more than another i.e. spending an hour working on schedule

\footnotetext{
${ }^{3}$ Filing costs include both the cost of filling out forms, record keeping, learning about the law and sending documents to the IRS. I estimate the cost of filing the 1040 form, Schedule A, Schedule B, Schedule C, Schedule D, Schedule E, Schedule F and Schedule SE. I do not have information on Schedule R.
} 
A is equally costly as spending an hour working on any other schedule. ${ }^{4}$ The third is that the IRS survey estimates of the number of hours required to file each schedule are accurate.

While the large magnitude of the costs could be explained by high levels of aversion to filing taxes, I gather empirical evidence suggesting that taxpayers procrastinate on filing their taxes which leads them to incur high costs. Procrastination makes two testable predictions: first, procrastinators will delay filing until the deadline and second, taxpayers who file close to the deadline will forgo more deductions. I provide empirical evidence consistent with both predictions and show that late filing is a persistent behavior confirming that it is a systematic bias.

The results of this paper have implications in several dimensions. First, this is the only paper to provide estimates of the cost of filing taxes using a quasiexperimental design. The most related paper is Pitt and Slemrod (1989): they estimate the cost of itemizing deductions using a censored model with unobserved censoring thresholds using maximum likelihood and find a smaller cost of itemizing of $\$ 107$. They use estimators from Gronau (1973) and Nelson (1977) to address the fact that the distribution below the standard deduction is unobservable. While our approaches are related, my method is able to provide reduced form demonstration of the existence of compliance costs without relying on a structural model. In both cases, assumptions are required to estimate the magnitude of the compliance costs, but fewer in my case. ${ }^{5}$ There is also a literature that uses survey evidence to estimate compliance costs. ${ }^{6}$ Although informative of the time spent filing taxes, it does not capture the preferences of taxpayers and in particular any aversion to filing taxes or any behavioral biases. It also suffers from the usual biases of surveys including high attrition rates and measurement errors. ${ }^{7}$

Finally, this paper adds to a long tradition in public economics emphasizing the need to screen out applicants for welfare benefits by imposing high hassle

\footnotetext{
${ }^{4}$ Complexity of the return is already included in the number of hours.

${ }^{5}$ I discuss their approach in more details in appendix section A

${ }^{6}$ See for example Slemrod (1989). The compliance costs estimated by this literature are listed in table I.8.

${ }^{7}$ Slemrod and Sorum (1984) and Slemrod (1989) report an attrition rate of $71.3 \%$.
} 
$\operatorname{costs}^{8}$ such as waiting in line, filling out forms etc. If poorer individuals value their time less - possibly because they are unemployed - then such policies can successfully target them by screening out richer individuals. My results show that this effect is indeed true because richer individuals tend to forgo more benefits than poorer ones. However, given how large hassle costs are, such policies could be screening out too many individuals. In addition, time inconsistency could lead to unwanted distortions such as screening out procrastinators versus nonprocrastinators rather than rich versus poor individuals.

\section{Data and Institutional Background}

\subsection{The Decision to Itemize Deductions}

Taxpayers can reduce their taxable income by claiming deductions. Consider, for example, a single person with an income of $\$ 150,000$ in the $28 \%$ marginal tax bracket. If she spends a total of $\$ 10,000$ on deductible expenses, her tax liability is reduced by $\$ 2,800$. If instead she decides to claim the standard deduction which in 1989 was $\$ 3,100$ - her tax liability is reduced only by $\$ 868$.

The decision to itemize deductions requires comparing two numbers: the sum of itemized deductions to the standard deduction amount. Itemizing however is administratively costly as it requires collecting several documents and working through a separate tax form.

Approximately two thirds of the population claim the standard deduction. The standard deduction amount varies by filing status (single, joint, married fling separately and head of household) and by whether the person is blind or older than 65 .

\subsection{The Cost of Itemizing}

Itemizing deductions is a two-step process. First, the taxpayer has to keep a record of all the expenses she wants to deduct during the year she is filing taxes for, year $t$. Second, she has to file a separate form when itemizing: Schedule A.

The majority of taxpayers itemize four types of deductions:

- State and local income taxes: these are taxes paid in year t to the state or to the locality. They are reported on form W2 received in January of year $t+1$. On average they represent $17 \%$ of total deductions.

\footnotetext{
${ }^{8}$ Nichols et al. (1971) and Duclos (1995).
} 
- Mortgage interest: this is the interest paid to finance the main or second home of the taxpayer. It is reported on form 1098 which is received in January of year $t+1$. On average they represent $40 \%$ of total deductions.

- Real estate taxes: these are taxes paid on real estate owned by the taxpayer. They can be found in financial records or by calling the county tax assessor. On average they represent $14 \%$ of total deductions.

- Charitable donations: any payment made for charitable purposes including to religious institutions. Except for vehicle donations in excess of $\$ 500$, these payments are not subject to third-party reporting. There are, however, documentation requirements for large donations. ${ }^{9}$ In addition, taxpayers need to keep records of their own receipts. On average charitable donations represent $12 \%$ of total deductions.

In addition, some taxpayers can also deduct other taxes (sales taxes in some years), other interest expenses (credit-card interest in some years), casualty or theft losses, medical and dental expenses and miscellaneous deductions.

Schedule A is relatively easy to fill out especially if the taxpayer only needs to itemize the most common deductions outlined above. All she has to do is copy numbers from form 1098, form W2 or charitable contribution receipts, sum them up and copy the sum in the 1040 form. There are no complicated tax schedules nor intricate tax operations. Record keeping is more time consuming as one has to archive the various evidence of expenses to be able to recover them when the tax season arrives. It is however easier to keep track of deductions that are thirdparty reported given that taxpayers receive the W2 and 1098 in January of year $t+1$.

\subsection{Data}

The dataset used to carry this analysis consists of annual cross sections of individual tax returns. It is constructed by the IRS and called the Individual Public Use Tax Files. They are commonly referred to as the Statistics of Income (SOI) files. The data is available annually for the periods that I am analyzing. The number of observation per year ranges from 80,000 to 200,000. The repeated cross sections are stratified random samples where the randomization occurs over the Social Security Number. The data over samples high-income taxpayers as well

\footnotetext{
${ }^{9}$ Property donations in excess of $\$ 500,000$ require an appraisal.
} 
as taxpayers with business income but weights are provided by the IRS and used in this analysis to produce estimates representative of the total US population. All the analysis in this paper uses these weights to reflect population averages. In addition, I use a panel of tax returns known as the University of Michigan tax panel. The panel covers 1979 to 1990 and contains the same variables as the SOI files but has a smaller sample size (less than 40,000 observations per year). Sample restrictions for each figure and table are detailed in appendix section $\mathrm{C}$.

\section{Missing Mass}

If some taxpayers are claiming the standard deduction when the sum of their itemized deductions is greater than the standard deduction there should be a missing mass just above the standard deduction threshold. I graph the density of deductions for years 1980, 1985, 1990, 1995, 2000 and 2005 in Figure 1 by bin sizes of $\$ 2,000$ in figure $1 .{ }^{10}$ The bin closest to the standard deduction only includes itemizers whose deductions are strictly larger than the standard deduction amount. Notice that the density is systematically low just above the standard deduction and then increases and peaks 2 to 3 bins away. This holds true across all years from 1980 to 2006 and for all filing status. Since I cannot observe the distribution of itemizers below the standard deduction, this cross-sectional evidence does not prove that the missing mass is caused by the standard deduction, and one could argue that is but a naturally occurring feature of the distribution. ${ }^{11}$

To prove that the missing mass is a distortion due to the standard deduction, I turn to a quasi-experimental design. There were four large increases in the standard deduction amounts since 1960. These changes occurred in 1971, 1975, 1988 and 2003. I use the 1988 reform to estimate the cost of itemizing because there are other changes that occur at the same time as the 1971, 1975 and 2003 reforms. In particular, the 2003 reform is likely to provide a lower bound on the cost of itemizing since there were changes in marginal tax rates and deduction rules that made it more attractive to itemize. In 1971 and 1975 there were changes to the parallel standard deduction system. ${ }^{12}$ Although the magnitude of

\footnotetext{
${ }^{10}$ All remaining years from 1980 to 2006 are plotted in appendix Figures H.10, H.11, H.12, H.13 and H.14. All dollar amounts are in 2016 dollars in the rest of the paper.

${ }^{11}$ Appendix figure H.22 shows different alternative scenarios that could create a missing mass.

${ }^{12}$ More details about the parallel system of standard deduction and other changes are provided in $\mathrm{E}$.
} 
the estimated cost for the 1971, 1975 and 2003 reforms is inaccurate, they still provide reduced-form evidence of the existence of compliance costs.

I compare the pre-1988 reform year to the post-reform year to account for lagged behavioral responses. Figures $2 \mathrm{a}$ and $2 \mathrm{~b}$ graph the density of deductions in pre and post-reform years for the 1988 reform. ${ }^{13}$ Notice that the shape of the distribution in year $\mathrm{t}+1$ mirrors that of years $\mathrm{t}$ and $\mathrm{t}-1$ and that the missing mass precisely follows the new standard deduction threshold. This shows that some itemizers switch to the standard deduction once it is increased even though their deductions are larger than the standard deduction.

The fact that the missing mass closely follows the standard deduction establishes that there is a discontinuity in the distribution caused by the standard deduction. If this missing mass was a feature of the distribution and not due to the standard deduction, it should not track the standard deduction once it is increased.

\section{Cost Estimation}

\subsection{Cost Estimation Methodology}

To calculate the distribution of forgone benefits in the population, I need to reconstruct the counterfactual distribution of itemizers. Using the pre-reform year as the counterfactual distribution would lead to an underestimate of the cost because the pre-reform distribution is distorted by its proximity to the standard deduction, as can be seen in figure 2a. This section explains how I reconstruct the counterfactual distribution.

Denote by $f(\cdot)$ the unobserved p.d.f. of itemizers assuming there is no standard deduction and no cost of itemizing as illustrated in Figure 3. Denote by $g_{S}(\cdot)$ the observed probability density function (p.d.f.) of itemizers when the standard deduction is equal to $S$. Then $g_{0}(\cdot)$ and $g_{\delta}(\cdot)$ respectively correspond to the pre- and post-reform p.d.f. of itemizers when the standard deduction increases from 0 to $\delta$. The cumulative distribution function (c.d.f.) of the cost of itemizing is denoted by $C_{S}(\cdot)$ and is defined over $\left[0, c_{\max }\right]$, where $c_{\max }$ denotes the largest cost an individual can have. ${ }^{14}$ Individuals whose total deductions exceed

\footnotetext{
${ }^{13}$ Appendix Figure H.16 report these densities for the 1971, 1975 and 2003 reforms and shows that the changes are qualitatively consistent with the 1988 reform.

${ }^{14}$ No assumptions about the drivers of the cost are needed in this section: $C_{S}(\cdot)$ can be due
} 
the standard deduction by less than the cost of itemizing choose the standard deduction. Formally,

$$
\forall S=\{0 ; \delta\}: \quad g_{S}(d)= \begin{cases}0, & \text { if } d \leq S \\ f(d)\left(1-C_{S}(d-S)\right), & \text { if } S<d \leq c_{\max }+S \\ f(d), & \text { if } d>c_{\max }+S .\end{cases}
$$

By rearranging $(1)$ over $d \in\left[0, c_{\max }\right]$ :

$$
C_{S}(d-S)=\frac{f(d)-g_{S}(d)}{g_{S}(d)}
$$

In other words the cost of itemizing is related to the missing mass $f(d)-g_{S}(d)$ which is shown in Figures 1, 2a and 2b. However, because $f(\cdot)$ cannot be observed directly, it needs to be reconstructed using $g_{0}(\cdot)$ and $g_{\delta}(\cdot)$. Two assumptions are necessary:

- A1: Cost is constant across years.

- A2: Cost is independent of the level of deductions.

Assumptions A1 and A2 imply that $C_{0}(\cdot)=C_{\delta}(\cdot)$, and from equation (2) follows that:

$$
C_{0}(d)=\frac{f(d)-g_{0}(d)}{g_{0}(d)}=\frac{f(d+\delta)-g_{\delta}(d+\delta)}{g_{\delta}(d+\delta)}=C_{\delta}(d),
$$

this implies that the same proportion of individuals is missing $d$ deductions above the pre-reform standard deduction and $d+\delta$ deductions above the post-reform standard deduction.

Assumption A1 can be verified by graphing two densities in years with no reforms and ensuring that they are overlapping. This assumption is verified on all years from 1980 to $2006 .{ }^{15}$ A failure of A2 introduces a relatively small bias in the cost estimate: in appendix section B, I provide an upper bound on the size of this bias and show that it is small. ${ }^{16}$

to the sum of the costs of record-keeping and filing or also include fear of audits and uncertainty which we discuss in section 5 .

${ }^{15}$ See appendix figure H.17.

${ }^{16}$ For joint filers in the $28 \%$ bracket for example, the estimated cost would lie between $\$ 572$ and $\$ 644$ if A2 fails, instead of $\$ 644$. 
To estimate $C(\cdot)$ and reconstruct $f(\cdot)$, I proceed in three steps. First, if $d \in\left[\delta+c_{\max } ;+\infty\right]$ then the benefit of itemizing is greater than its cost both preand post-reform and taxpayers will not forgo deductions by claiming the standard deduction. This corresponds to the rightmost area in Figure 3. Formally, if $d \in\left[\delta+c_{\max } ;+\infty\right]$ then $C(d)=1$ and $g_{\delta}(d)=g_{0}(d)=f(d)$ i.e. the pre- and post-reform distributions of itemizers overlap for ranges of deductions exceeding the post-reform standard deduction $\delta$ by more than the largest possible cost $c_{\max }$. And for any $d \in\left[\delta+c_{\max } ;+\infty\right], f(d)=g_{0}(d)$ i.e. the pre-reform observed distribution of itemizers $g_{0}(\cdot)$ corresponds to the undistorted distribution $f(\cdot)$.

Second, if $d \in\left[c_{\max } ; \delta+c_{\max }\right]$ then over this range, the pre-reform taxpayers do not forgo any deductions but the post-reform ones will. This corresponds to the middle area in Figure 3. As a consequence, the pre-reform distribution is not affected by its proximity to the standard deduction and is equal to the undistorted distribution i.e. $g_{0}(d)=f(d)$, but the post-reform distribution is distorted i.e. $g_{\delta}(d)<f(d)$. From equation (3) it follows that $\forall d \in\left[c_{\max } ; \delta+c_{\max }\right]$ :

$$
C(d-\delta)=\frac{f(d)-g_{\delta}(d)}{g_{\delta}(d)}=\frac{g_{0}(d)-g_{\delta}(d)}{g_{\delta}(d)}
$$

this allows me to estimate $C(\cdot)$ over $\left[c_{\max }-\delta ; c_{\max }\right]$.

Third, if $d \in\left[c_{\max }-\delta, c_{\max }\right]$ then both the pre-reform and post-reform itemizers are forgoing deductions. This corresponds to the leftmost area in Figure 3. In this case, both the pre- and post-reform distributions are distorted by their proximity to the standard deduction and $g_{0}(\cdot)$ is now different from $f(\cdot)$. To reconstruct $f(\cdot)$, I use the estimate of $C(\cdot)$ over $\left[c_{\max }-\delta ; c_{\max }\right]$ from equation 4 to correct the pre-reform distribution by using the definition of $g_{0}(\cdot): f(d)=g_{0}(d)(1+C(d))$. From equation 3 follows that $\forall d \in\left[c_{\max }-\delta ; c_{\max }\right]$

$$
C(d-\delta)=\frac{f(d)-g_{\delta}(d)}{g_{\delta}(d)}=\frac{g_{0}(d)(1+C(d))-g_{\delta}(d)}{g_{\delta}(d)}
$$

this allows me to estimate $C(\cdot)$ over $\left[c_{\max }-2 \delta ; c_{\max }-\delta\right]$. By repeating this procedure over $\left[c_{\max }-3 \delta ; c_{\max }-2 \delta\right],\left[c_{\max }-4 \delta ; c_{\max }-3 \delta\right]$ etc. I can recover $C(\cdot)$ and $f(\cdot)$ over $\left[0, c_{\max }\right]$. 


\subsection{Cost Estimates}

I apply the methodology outlined above to the 1988 reform which increased the standard deduction from $\$ 2,540$ to $\$ 3,000$ for single filers, from $\$ 3,760$ to $\$ 5,000$ for joint filers and from $\$ 2,540$ to $\$ 4,400$ for head of households filers. Besides the standard deduction reform, the only reform happening in 1988 that could affect the amount of deductions is the phase out of the personal interest deduction, which I control for (details in section 5.5). There were no other reforms affecting deductions in 1988 or 1989 and the reforms affecting the 1987 distribution do not have lagged effects. ${ }^{17}$ Each cost estimate is performed on individuals with the same marginal tax rate and who are not subject to the Alternative Minimum Tax (AMT). There is a marginal tax rate decrease for married filing jointly with income above $\$ 45,000$ (in 1987 dollars) in 1988. I address this by estimating the cost separately for individuals above and below this cutoff.

I use 1989 as the post-reform year rather than 1988 because the reform occurs in 1988. If taxpayers learn about the increase in the standard deduction when filing their taxes, we should observe the full response in 1989. Figure 2b confirms that the effect is smaller during the reform year.

Table 1 shows the estimated costs for single, joint and head of households filers in the $15 \%$ and $28 \%$ marginal tax brackets. Costs vary from $\$ 175$ for single filers in the $15 \%$ bracket to $\$ 591$ for joint filers in the $28 \%$ bracket. Costs are systematically lower for individuals in lower tax brackets, suggesting that income matters in determining the cost as is shown in the next section.

To calculate the standard errors of the difference between the bins in the 1987 and 1989 densities, I use a bootstrap procedure. The results are reported in table 2. The difference between the first and second bins is statistically significant with large $\mathrm{z}$ statistics (6.55 and 3.47). The rest of the bins are all overlapping with differences that are not significant even at the $10 \%$ level, at the exception of bin 10, 11 and 13 that are statistically significantly different at the 5 and $10 \%$ level, with differences of very small magnitude (less than 10 times that of the first or second bins).

\footnotetext{
${ }^{17}$ See section 5.5 for the full list of reforms and appendix section D for the TRA' 86 reforms.
} 


\section{Anatomy of the Missing Mass}

\subsection{Costs Increase With Income}

If rich taxpayers value their time more than poor ones because their hourly wage is higher, we should expect them to forgo more deductions. I can test this using the income reported on tax returns. To do so, I break down the sample used above by deciles of income. This raises power issues that I deal with in two ways. First, I use a moving average of the income deciles. For example, the lower income group consists of every individual with income below the second decile threshold. And the second group consists of taxpayers with income above the first decile and below the third decile etc. Second, I focus on joint filers in the $28 \%$ marginal tax bracket as they represent by far the largest group of taxpayers.

Once the groups are constructed, I fit a polynomial of degree 3 through each deduction bin. I then calculate the difference in density for each bin. When this difference is not statistically significant, I consider that the bins are overlapping and therefore no deductions are forgone in that specific bin. Using the predicted bins from this polynomial, I calculate the forgone benefits for each group by repeating the procedure developed in the previous section: I compare the distribution in 1987 to that in 1989, reconstruct the counterfactual distribution of itemized deductions and calculate the distribution of the cost of itemizing by comparing the counterfactual distribution to the true one. I only report results for the first seven groups because deductions and income are positively correlated implying that there are very few high income individuals close to the standard deduction threshold making the estimates for these bins uninformative. ${ }^{18}$ The results are plotted in Figure 4(a): as income increases taxpayers forgo more benefits consistent with the idea that they value their time relatively more. Two pieces of information are worth emphasizing: first, all taxpayers in figure 4(a) fall in the $28 \%$ marginal tax bracket, implying that the positive relationship between income and forgone benefits is not due to marginal tax rate variation but rather to income per-se. Second, even though itemized deductions increase with income, this is not what drives the increasing relationship between income and forgone benefits. Because I am using a quasi-experimental design, and compare the same

\footnotetext{
${ }^{18}$ The remaining two income bins are reported in appendix Figure H.21.
} 
income groups before and after the reform, I am implicitly controlling for the relationship between income and deductions.

\subsection{Tax Preparers and Electronic Filing}

Electronic filing and the use of tax preparers may reduce the cost of filling out forms as one need not file schedule A. However, it does not affect the cost of record keeping. Therefore, if record keeping costs are non-zero, electronic filing or the use of tax prepapers will not reduce costs to zero and one will still observe a missing mass close to the standard deduction threshold. That record keeping is the driver of the cost of itemizing has been consistently documented by survey estimates of the cost of filing taxes. ${ }^{19}$

To test for whether electronic filing or using a tax preparer eliminates the cost of itemizing, I graph the density of itemizers who use a tax preparer and those who use electronic filing in graph 5 and look for whether there is still a missing mass close to the standard deduction threshold. The missing mass is still present implying that tax preparers or electronic filing does not eliminate the cost of itemizing.

Figure 5(b) compares the density of taxpayers who use electronic filing to those who do not. It shows a slightly smaller - but statistically significant missing mass for taxpayers who file electronically than those who do not. The difference is statistically significant. ${ }^{20}$ This is consistent with the missing mass being driven by taxpayers claiming the standard deduction to avoid the cost of itemizing. However, electronic filing only slightly reduces the cost of itemizing and does not eliminate the missing mass, consistent with record-keeping being the main driver of compliance costs.

I cannot perform a similar test for taxpayers who use tax preparers as the two densities do not overlap away from the standard deduction - possibly because the population that uses tax preparers is intrinsically different from the population that does not - making a comparison of the missing mass impossible. Figure 5 (a) shows however that the use of tax preparers does not eliminate the cost of itemizing.

\footnotetext{
${ }^{19}$ See for example Guyton et al. (2003), Slemrod and Sorum (1984), Slemrod and Bakija (2008) and Blumenthal and Slemrod (1992).

${ }^{20}$ Bootstrapped standard errors are reported in table I.6
} 


\section{Alternative Explanations to Compliance Costs}

\subsection{Information}

Information or cognitive abilities are unlikely to explain the forgone deductions. I focus on taxpayers who switch from itemizing to claiming the standard deduction, therefore they should be well aware of the decision to itemize and have the cognitive abilities to do so. In addition, taxpayers are reminded on the 1040 form of the fact that they can itemize deductions as they have to make an active decision between itemizing and claiming the standard deduction.

\subsection{Evasion}

An alternative explanation for the presence of a missing mass is that taxpayers are concerned with being audited by the IRS. They mistakenly believe that audit probabilities are higher when itemizing. Their beliefs over audit probabilities could lead them to switch to the standard deduction once it increases to avoid the expected cost of an audit.

Audit probabilities are very low, therefore for this behavior to explain the missing mass, taxpayers would need to mistakenly believe that audit probabilities are high or that audit costs are large. To address this, I carry a survey of 195 individuals in a wealthy neighborhood of the city of Los Angeles to capture as many itemizers as possible. Appendix section F details the survey instrument. The survey allows me to elicit their beliefs over both the audit probabilities for itemizers and the perceived costs of undergoing an audit. The results of the survey are reported in figure 9.

Surveyed individuals have similar levels of income as joint filers in the 1988 $28 \%$ marginal tax bracket. On average, they believe that audits occur with a probability of $8.72 \%$, which is 7.9 times the true audit probabilities. ${ }^{21}$ This accounts for at most $25 \%$ of the $\$ 591$ estimated forgone benefits for joint filers in the $28 \%$ marginal tax bracket. ${ }^{22}$

\footnotetext{
${ }^{21}$ This is consistent with Bhargava and Manoli (2015) who find that EITC filers believe that audit probabilities are 8 times larger than the true ones.

${ }^{22} \mathrm{On}$ average, their willingness to pay to avoid an audit is $\$ 1,748$, which implies that the expected cost of an audit is $\$ 147$, with a $95 \%$ confidence interval of $[126,169]$.
} 


\subsection{Concave Kink Points}

When claiming the standard deduction, taxpayers are paying the full cost of charitable donations, mortgage interest etc. they may have incurred below the standard deduction. However, when they itemize, they only pay a portion of it because deductions are subsidized by 1 minus the marginal tax rate. The standard deduction acts as a concave kink point: the price of charitable donations is lower when itemizing than when claiming the standard deduction. The indifference curve of a given taxpayer can be tangent at two points of the concave kinked budget set (see figure 6(a)), possibly inducing some taxpayers to be indifferent between two points, one above the standard deduction and one below it. Depending on the curvature of the indifference curve, this could create a bi-modal distribution with a missing mass both to the right and to the left of the standard deduction (see figure 6(b)).

However, according to the assumption that taxpayers respond to concave kink points, the size of the missing mass should not respond to variations in income when controlling for the marginal tax rate. The only reason taxpayers should adjust their deductions in response to a concave kink point is because of the marginal tax rate and income should not matter per se in this case. On the other hand, a behavioral response due to compliance costs predicts that richer taxpayers will forgo more money because they have a higher opportunity cost of time even controlling for the marginal tax rate. Figure 4 graphs the relationship between forgone benefits and income - controlling for the marginal tax rate and finds an increasing relationship, rejecting the hypothesis that taxpayers are responding to concave kink points in this setting.

In addition, behavioral responses to concave kink points lead individuals to locate away from the concave kink point. This mechanism is illustrated in figure 6. If behavioral responses to concave kink points were leading to the observed missing mass, as the standard deduction increases, the bi-modal distribution should track the new standard deduction threshold as illustrated in figure 6(c) and the pre and post-distribution peaks should not overlap. The observed pre and post distributions in Figures $2 \mathrm{a}$ and $2 \mathrm{~b}$ contradict the prediction of figure 6(c): the pre and post distribution peaks are overlapping rejecting again that the missing mass is caused by behavioral responses to concave kink points. 
Overall, both the fact that forgone deductions increase with income and the shape of the post reform distribution of deductions rule out responses to concave kink points. The absence of behavioral responses to concave kink points is consistent with the empirical public finance literature that documents behavioral responses to tax systems and does not find any evidence of responses to concave kink points. Saez (2010), Kleven and Waseem (2013) and Tazhitdinova (2015) directly test the predictions of a behavioral response to both concave and convex kink points, find responses to convex kink points but no responses to concave kink points. For example, Saez (2010) finds evidence of bunching at the threshold of the first income tax bracket where tax liability starts and at the first kink of the EITC - which are both convex kinks - but no evidence of bunching at the second EITC kink - which is concave. Kleven (2016) in a survey of the bunching literature confirms that there is no evidence of bunching at concave kink points.

\subsection{Rational Inattention}

Can uncertainty over the level of deductions lead a taxpayer to switch to the standard deduction and explain the observed missing mass? Table 3 shows the results of the calibration of a model illustrative of this type of behavior with varying levels of risk aversion. ${ }^{23}$ Taxpayers would need an uncertainty range of at least $\pm \$ 14,000$ for them to forgo similar amounts of money as found in this paper when their true deductions are $\$ 10,000$. This uncertainty range is large and unlikely given that I focus on taxpayers who were itemizing the year before and because total deductions are highly serially correlated across years for a given individual since $71 \%$ of total deductions are mortgage interest, state taxes and real estate taxes which are relatively stable for a given person year after year.

\subsection{Other Reforms Affecting Deductions?}

Other changes happened in 1988. In this section, I describe these changes and explain how I adjust for the ones that are likely to affect my estimates. The estimates derived in section 3 already accounted for these adjustments. The fact that the pre and post-reform densities overlap away from the standard deduction threshold shows that the pre-reform density is a relevant counterfactual for the post-reform density in figure $2 \mathrm{a}$ and that - after adjusting for these changes -

\footnotetext{
${ }^{23}$ The model is outlined in appendix section $\mathrm{G}$.
} 
the missing mass estimates are not affected by these changes.

The personal interest deduction was phased out starting from 1986. In 1987, taxpayers could only deduct $65 \%$ of their personal interest, $40 \%$ in 1988 and $20 \%$ in 1989. This is likely to affect the distribution of deductions from 1987 to 1989. To control for this effect, I adjust the 1987 distribution - which is the counterfactual for 1989 - by recalculating the personal interest deduction as if only $20 \%$ of it could be deducted. This leads some taxpayers to have deductions below the standard deduction whom I drop. To ensure that there is no behavioral effect associated with the phasing out of the personal interest deduction, I compare the distribution of deductions for individuals below the $28 \%$ marginal tax rate bracket and above. If there was a behavioral effect, we should observe more deductions for individuals above the $28 \%$ marginal tax bracket. I find no significant behavioral response of personal interest deductions. ${ }^{24}$ This is consistent with the fact that the majority of the personal interest deduction is claimed for interest on student loans which are hard to adjust once they are contracted. In addition, after making this correction, I can compare the overlap between the pre and postreform densities. Away from the standard deduction, the two graphs overlap implying that the post-reform density is an appropriate counterfactual for the 1989 density.

\section{Total Filing Costs Increase Over Time}

\subsection{Average Treatment Effect}

The cost I estimate is a local average treatment effect representative of filers who are just above the standard deduction. To get an average treatment effect, I need to estimate the cost for individuals away from the standard deduction threshold. These individuals differ in their demographics, in particular they are more likely to have different income levels since deductions and income tend to be positively correlated. For this reason, I need to estimate the effect that these demographics have on cost. I do so for four variables: income, dependents, use of tax-preparers and electronic filing.

To estimate the effect of dependents and use of tax-preparers on the cost of itemizing, I apply the procedure outlined in section 3.1 for the 1988 reform on

\footnotetext{
${ }^{24}$ See appendix figure H.23.
} 
subsamples of joint filers. I use joint filers to perform this subsample analysis because they represent more than $50 \%$ of the population of filers which is essential to getting enough power when breaking down the main sample into multiple groups. This means that my approach relies on the assumption that these demographics affect filing costs the same way for different types of filers and for different years. To estimate the effect of tax-preparers, I compare the cost for joint filers who use a tax preparer to those that do not. I use a similar approach for taxpayers with and without dependents. To estimate the effect of income on the cost of filing, I use the estimates from section 4.1. Because electronic filing did not exist in 1988, I cannot use the procedure from section 3.1. Instead, I pool all cross-sections in years when electronic-filing was commonly used - 1998 to 2006 -, fit a polynomial through the bins that are away from the standard deduction to extrapolate the counterfactual distribution close to the standard deduction and compare the distribution of electronic-filers and paper-filers to this counterfactual to assess the size of the missing mass for each group. ${ }^{25}$ Formally, I assume that filing cost is given by the following equation:

$$
\begin{aligned}
C= & \beta *\left\{\left[\left(\alpha_{e f i} \mathbb{1}_{e f i}+\alpha \overline{e f i}\left(1-\mathbb{1}_{\text {efi }}\right)\right]+\left[\alpha_{\text {prep }} \mathbb{1}_{\text {prep }}+\alpha_{\overline{\text { prep }}}\left(1-\mathbb{1}_{\text {prep }}\right)\right]\right.\right. \\
& +\left[\alpha_{\text {dep }} \mathbb{1}_{\text {dep }}+\alpha_{\overline{d e p}}\left(1-\mathbb{1}_{\text {dep }}\right)\right]+\sum_{i=0}^{9} \alpha_{i} \mathbb{1}_{i}
\end{aligned}
$$

where $\beta$ is the baseline cost of itemizing as estimated in section 3.1, $\alpha_{e f i}$ is the effect of electronic filing on the cost of itemizing, $\alpha \overline{e f i}$ is the effect on cost of not filing electronically. The remaining variables are defined similarly, with prep corresponding to the use of a tax preparer and dep having at least one child dependent. Each $\alpha_{i}$ coefficient corresponds to the effect of income on the cost. They are derived in section 4.1: each $\alpha_{i}$ is equal to the ratio of the cost of itemizing for income group $i$ divided by the average cost of itemizing for all groups. The coefficients are reported in Table 1.

\subsection{Other Schedules}

To infer the cost of filing other schedules, I assume that holding constant the number of hours spent working on a given tax schedule, taxpayers derive the

\footnotetext{
${ }^{25}$ The three distributions are shown in Figure H.20.
} 
same disutility from each tax schedule. In other words, they do not dislike filing particular schedules more than others as long as they require the same number of hours. I also assume that the demographics estimated in section 6.1 affect the cost of other schedules in the same way. The IRS provides estimates of the number of hours required to file each tax schedule based on surveys of taxpayers at the time of filing. ${ }^{26}$ I use these survey estimates to scale the cost estimates of other schedules. For example, filing schedule B requires 1 hour and 19 minutes, which is $28 \%$ the total time required to file schedule A, so I assign a baseline cost of filing schedule B of $28 \%$ of that of schedule A. The filing cost for each taxpayer is given by a similar equation as equation (6), with a subscript $x$ that corresponds to each tax schedule:

$$
\begin{aligned}
C_{x}= & \beta_{x} *\left\{\left[\left(\alpha_{\text {efi }} \mathbb{1}_{\text {efi }}+\alpha_{\overline{\text { efi }}}\left(1-\mathbb{1}_{\text {efi }}\right)\right]+\left[\alpha_{\text {prep }} \mathbb{1}_{\text {prep }}+\alpha_{\overline{p r e p}}\left(1-\mathbb{1}_{\text {prep }}\right)\right]\right.\right. \\
& \left.+\left[\alpha_{\text {dep }} \mathbb{1}_{\text {dep }}+\alpha_{\overline{d e p}}\left(1-\mathbb{1}_{\text {dep }}\right)\right]+\sum_{i=0}^{9} \alpha_{i} \mathbb{1}_{i}\right\}
\end{aligned}
$$

Where $C_{x}$ is the cost of schedule $x=1040, A, B, C, D, E, F, S E$ and $\beta_{x}$ is the baseline cost estimate of schedule $x$. The coefficients are reported in Table 1.

\subsection{Costs Have Been Increasing Since the 1980's}

Using equation (7), I estimate the total cost of filing all schedules of the federal income tax for every year from 1984 to $2006 .^{27}$ Figure 7 a shows that costs have been increasing steadily from $\$ 150$ bn in 1984 to $\$ 200$ bn in 2006 (both in 2016 dollars). Part of this increase is mechanically driven by an increase in the number of tax filers. But, it is also driven by a steady increase in the number of taxpayers who have to file other schedules in addition to the 1040 form. Some of these schedules require a substantial amount of time to be filed. Figure $7 \mathrm{~b}$ plots the number of forms filed by schedule over time. The proportion of non-1040 forms filed increased by $15 \%$ from 1984 to 2009. While it is often believed that filing costs decreased over time since the 1980's because of the rapid increase of electronic filing, Figure $7 \mathrm{~b}$ shows that there are two countervailing forces to elec-

\footnotetext{
${ }^{26}$ According the IRS survey estimates, the 1040 form requires 9.4 hours, Schedule A 4.5 hours, Sch. B 1.3 hours, Sch. C 9.6 hours, Sch. D 3.8 hours, Sch. E 5.8 hours, Sch. F 16.1 hours and Sch. SE 1.1 hours. See appendix Table I.10 for a break-down of the cost.

${ }^{27} \mathrm{I}$ start in 1984 because prior years are missing information on Schedule SE.
} 
tronic filing which drive total costs upwards: the number of individuals who file taxes and the number of scheduled filed by each taxpayer. My estimates suggest the upward pressure on filing costs exerted by these two forces outweigh the cost savings of electronic filing. The number of non-1040 forms filed can be easily reduced by increasing the filing thresholds for their corresponding schedules. The cost savings from increasing these thresholds would need to be weighed against the effect they would have on increasing evasion. ${ }^{28}$

\section{Compliance Costs or Behavioral Costs?}

There is extensive evidence that individuals are time inconsistent and tend to procrastinate. ${ }^{29}$ If taxpayers procrastinate on filing their taxes, one should observe a large proportion of taxpayers filing on April 15th. And these taxpayers should forgo more deductions. ${ }^{30}$

First, consistent with individuals procrastinating on filing their taxes, I find that taxpayers bunch at the deadline of April 15th. Figure 8a graphs the volume of Google search of the term 1040 by week and figure 8b uses data from irs.gov ${ }^{31}$ and graphs the number of tax returns filed by week. Both exhibit a clear spike in the weeks that include April 15th. This is consistent with Hoopes et al. (2015) who show that that there are more calls made to the IRS close to April 15th and that taxpayers search more actively on Google and Wikipedia for capital-gainstax-related information.

Second, I also find that taxpayers who file close to the deadline tend to forgo more deductions consistent with procrastination accounting for a portion of the estimated forgone deductions. Figure $8 \mathrm{c}^{32}$ shows that the missing mass for close to the deadline filers (first two weeks of April) is larger than for March filers.

Note that rational taxpayers should not file close to the deadline for two reasons: by delaying filing, they forgo interest on their refunds and they expose themselves to higher filing costs. Indeed, the sample I use to generate figure $8 \mathrm{c}$ only includes taxpayers who are owed a refund by the IRS and therefore have an

\footnotetext{
${ }^{28}$ Tazhitdinova (2014) explores this tradeoff in the case of charitable donations.

${ }^{29}$ See DellaVigna (2009) for a survey of the literature.

${ }^{30} \mathrm{I}$ formalize this argument in appendix section $\mathrm{H}$ and show that procrastination can lead to high record keeping costs resulting in individuals failing to itemize.

${ }^{31}$ https://www.irs.gov/uac/2016-and-prior-year-filing-season-statistics

${ }^{32}$ Appendix section C.6 explains how the graph is constructed.
} 
incentive to file as early as possible to save on interest. ${ }^{33}$ Second, filing costs are substantially higher closer to the deadline because lines at the post office and tax preparers are longer and it is harder to get tax help from the IRS because their phone lines are busier than usual. ${ }^{34}$

Notice also that late filing is hard to reconcile with the option value of waiting for low cost realizations. One could argue that taxpayers who bunch at the deadline are rational taxpayers who wait for a low cost realization and face a series of idiosyncratic shocks that force them to file hastily at the very last moment and lead them to forgo benefits. If that is the case, then we should observe that taxpayers who file late in year $t$ are likely to file earlier in year $t+1$. To test for this, I graph the average week in which returns are processed in year $t+1$ by week of processing in year $t$, in figure $8 \mathrm{~d}$. If taxpayers who bunch at the deadline are doing so for rational reasons, the relationship should be constant as we should observe mean reversion. If they are doing so because of a systematic bias, the relationship should be increasing as year $t$ week of processing should predict year $t+1$ week of processing. Figure $8 d$ shows an increasing relationship - with a t-statistic equal to 49 - between processing week in year $t$ and year $t+1$ consistent with the explanation that late filing is due to a systematic bias.

\section{Conclusion}

Using a quasi-experimental design and a novel method to recover the counterfactual density of deductions, I find that taxpayers forgo large amounts of deductions. This implies tax filing costs of a much larger magnitude than previously estimated using survey methods. The aggregate cost of filing federal taxes has been steadily increasing over time since the 1980's in part because of population growth but also because of the increase in the number of forms filed by each taxpayer.

Should the cost of tax filing be reduced? The IRS faces a tradeoff between requiring less forms and receipts (and therefore reducing filing costs) versus reducing evasion. The large magnitude of my estimates suggests that reducing

\footnotetext{
${ }^{33}$ Slemrod et al. (1997) estimates that taxpayers forgo $\$ 46$ million in interest by not claiming their refund as soon as possible.

${ }^{34}$ Redelmeier and Yarnell (2012) for example report that there are more road crash fatalities on April 15th and argue that is due to taxes.
} 
reporting might be welfare improving even if it leads to higher evasion costs.

Filing costs can also be reduced without reducing reporting. This is especially true if taxpayers tend to procrastinate. The IRS can ensure that the deadline for filing taxes falls on a day when people are likely to be less busy such as the weekend. In addition, the IRS could shift the cost of filing taxes to firms since they are less likely to be subject to procrastination. This can be achieved through informational reporting as is the case with the mortgage deduction.

However, some compliance cost can be efficient when designing a tax system and can be used as a policy instrument. This is especially true when the social gains of deductions or loopholes are small and political economy concerns prevent the government from repealing these deductions. One way of ensuring that taxpayers do not claim them is to impose large compliance costs. ${ }^{35}$

Finally, the identification strategy used in this paper can be exported to estimate other compliance costs when individuals have a choice between a low cost low benefit option versus a high cost high benefit one as is the case for example when deciding whether to file a lawsuit in small claims court versus regular court. It can also be used when identifying responses from a censored distribution above or below a certain threshold.

\section{References}

Bertrand, M., S. Mullainathan, and E. Shafir (2006). Behavioral economics and marketing in aid of decision making among the poor. Journal of Public Policy \& Marketing 25(1), 8-23.

Bhargava, S. and D. Manoli (2015). Psychological frictions and the incomplete take-up of social benefits: Evidence from an IRS field experiment. The American Economic Review 105(11), 3489-3529.

Blank, R. and D. Card (1991). Recent trends in insured and uninsured unemployment: Is there an explanation? Quarterly Journal of Economics 106(4), 1157-1189.

Blumenthal, M. and J. Slemrod (1992). The compliance cost of the us individual income tax system. National Tax Journal, 185-202.

Currie, J. (2006). The take-up of social benefits. Public Policy and the Income Distribution, 80.

DellaVigna, S. (2009). Psychology and economics: Evidence from the field. Journal of Economic Literature $47(2), 315-372$.

\footnotetext{
${ }^{35}$ Discussed in Kaplow (1998).
} 
Duclos, J.-Y. (1995). Modelling the take-up of state support. Journal of Public Economics 58(3), 391-415.

Gronau, R. (1973). The effect of children on the housewife's value of time. The Journal of Political Economy, S168-S199.

Guyton, J., J. O'Hare, M. Stavrianos, and E. Toder (2003). Estimating the compliance cost of the US individual income tax. National Tax Journal, 673 -688 .

Handel, B. R. (2013). Adverse selection and inertia in health insurance markets: When nudging hurts. The American Economic Review 103(7), 2643-2682.

Holt, C. A. and S. K. Laury (2002). Risk aversion and incentive effects. American Economic Review 92(5), 1644-1655.

Hoopes, J. L., D. H. Reck, and J. Slemrod (2015). Taxpayer search for information: Implications for rational attention. American Economic Journal: Economic Policy 7(3), 177-208.

Kaplow, L. (1998). Accuracy, complexity, and the income tax. Journal of Law, Economics, and Organization 14(1), 61-83.

Keys, B. J., D. G. Pope, and J. C. Pope (2014). Failure to refinance. Working Paper.

Kleven, H. J. (2016). Bunching. Annual Review of Economics 8(1).

Kleven, H. J. and M. Waseem (2013). Using notches to uncover optimization frictions and structural elasticities: Theory and evidence from pakistan. The Quarterly Journal of Economics 129, 669-723.

Little, A. D. (1988). Development of methodology for estimating the taxpayer paperwork burden.

Madrian, B. and D. Shea (2001). The power of suggestion: Inertia in 401(k) participation and savings behavior. Quarterly Journal of Economics 116(4), 1149-1187.

Nelson, F. D. (1977). Censored regression models with unobserved, stochastic censoring thresholds. Journal of Econometrics 6(3), 309-327.

Nichols, D., E. Smolensky, and T. N. Tideman (1971). Discrimination by waiting time in merit goods. The American Economic Review, 312 -323.

Pitt, M. and J. Slemrod (1989). The compliance cost of itemizing deductions: Evidence from individual tax returns. The American Economic Review, 12241232 .

Redelmeier, D. A. and C. J. Yarnell (2012). Road crash fatalities on us income tax days. The Journal of the American Medical Association 307(14), 1486-1488.

Saez, E. (2010). Do taxpayers bunch at kink points? American Economic Journal: Economic Policy, 180-212.

Slemrod, J. (1989). The return to tax simplification: An econometric analysis. Public Finance Review 17(1), 3-27. 
Slemrod, J. and J. Bakija (2008). Taxing ourselves: a citizen's guide to the debate over taxes. MIT Press Books.

Slemrod, J., C. Christian, R. London, and J. A. Parker (1997). April 15 syndrome. Economic Inquiry 35(4), $695-709$.

Slemrod, J. and N. Sorum (1984). The compliance cost of the US individual income tax system. National Tax Journal, $461-474$.

Steuerle, E., R. McHugh, and E. M. Sunley (1978). Who benefits from income averaging? National Tax Journal, 19-32.

Sydnor, J. (2010). (over) insuring modest risks. American Economic Journal: Applied Economics 2(4), 177-199.

Tazhitdinova, A. (2014). Optimal reporting threshold: Theory and evidence from charitable contributions. Manuscript, UC Berkeley.

Tazhitdinova, A. (2015). Tax breaks for low earners: Who benefits from them? evidence from mini-jobs in germany. Working Paper.

Wicks, J. H. (1965). Taxpayer compliance costs from the montana personal income tax. Montana Business Quarterly 3, 36-42.

Wicks, J. H. and M. N. Killworth (1967). Administrative and compliance costs of state and local taxes. National Tax Journal, 309-315. 
Figure 1: Missing Mass Just Above the Standard Deduction

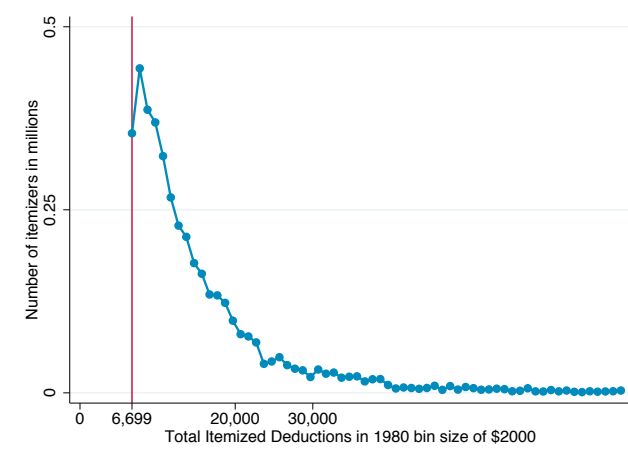

(a) 1980

花

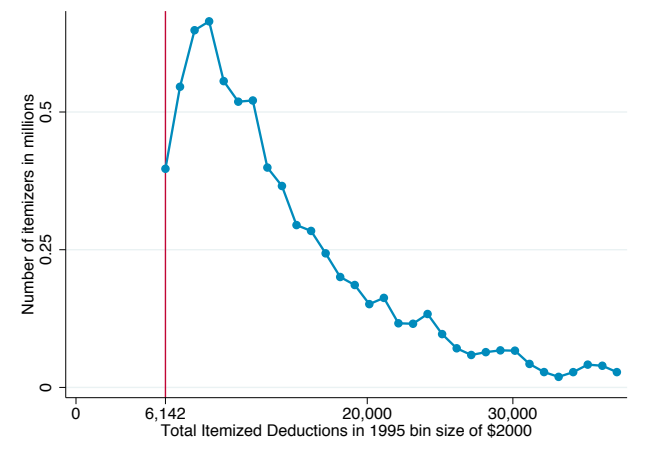

(d) 1995

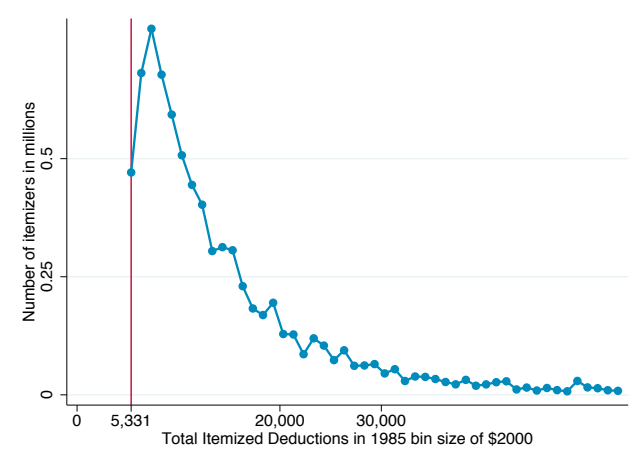

(b) 1985

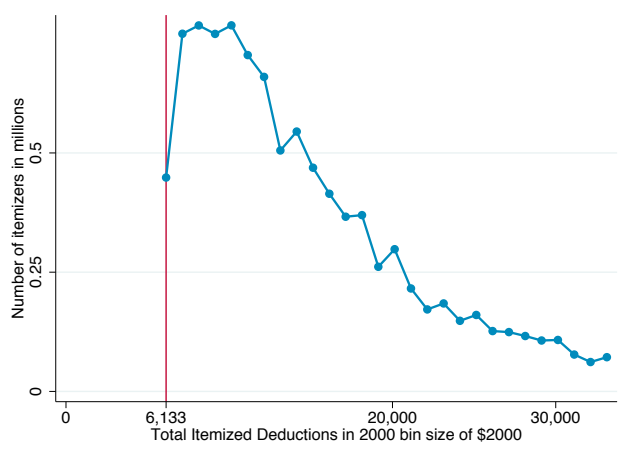

(e) 2000

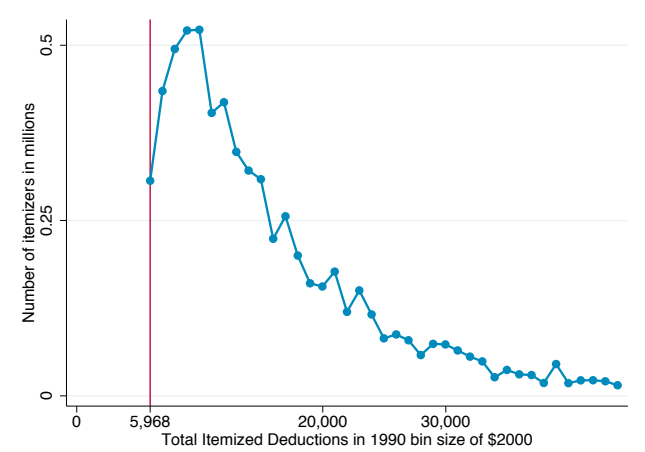

(c) 1990

Notes: The figures above plot the density of deductions for itemizers filing jointly. The bin size is $\$ 2,000$ and the vertical line represents the standard deduction threshold for each year. Additional years are reported in appendix figures H.11, H.12, H.13 and H.14 and figure H.15 for single filers. 


\section{Figure 2: Density of Deductions for Itemizers Filing Jointly Pre and Post Reform}

(a) 1987-1989 Comparison

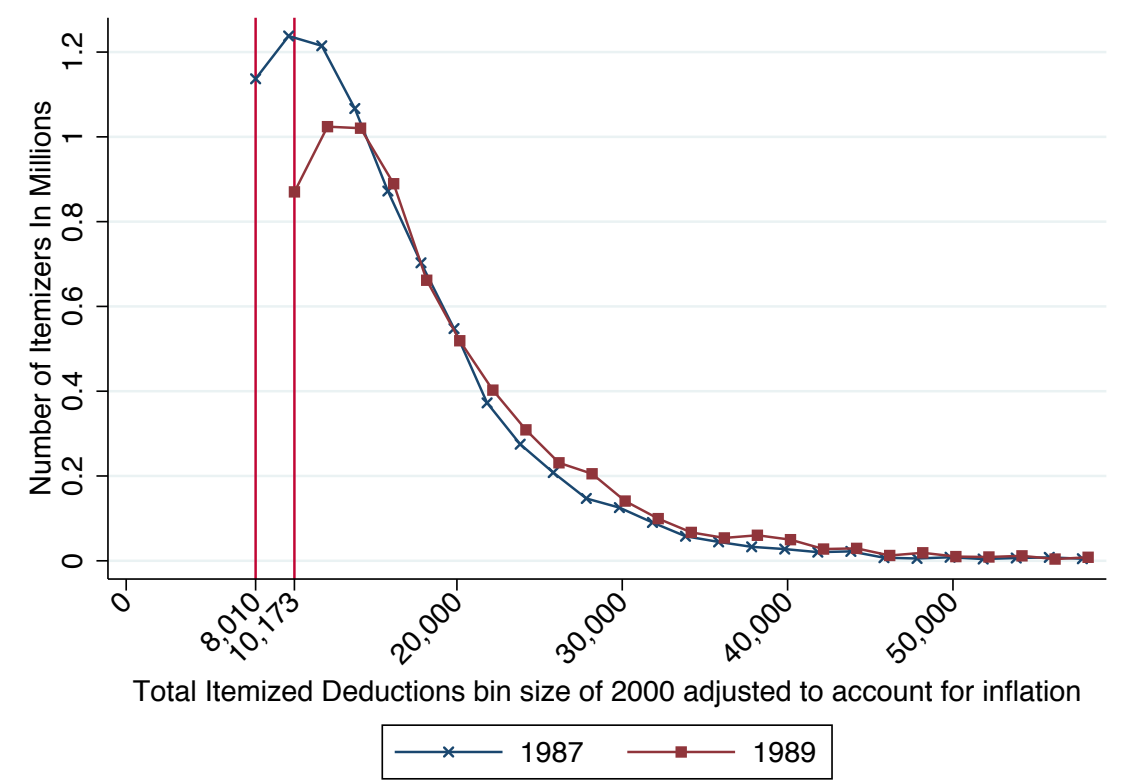

(b) 1987-1988 Comparison

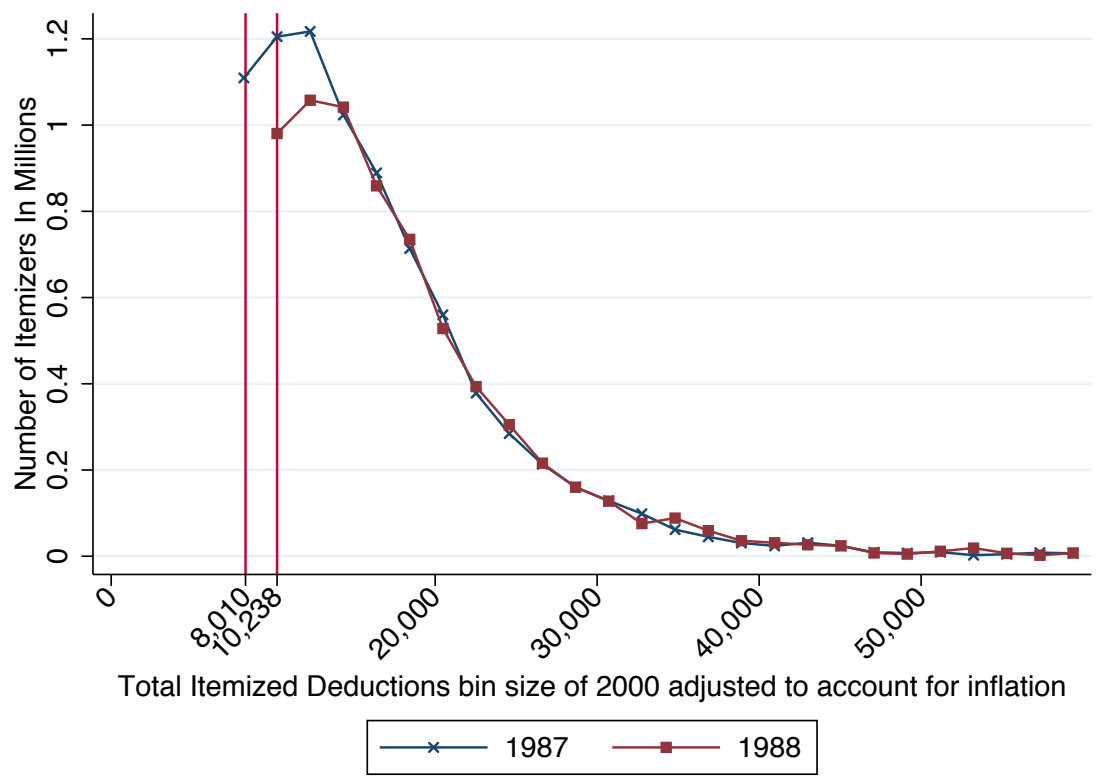

Notes: The first graph plots the density of itemizers one year before and one year after the standard deduction reform while the second one plots these densities one year before and during the reform. 


\section{Figure 3: Reconstruction of the Counterfactual Density}

(a) Procedure Illustration

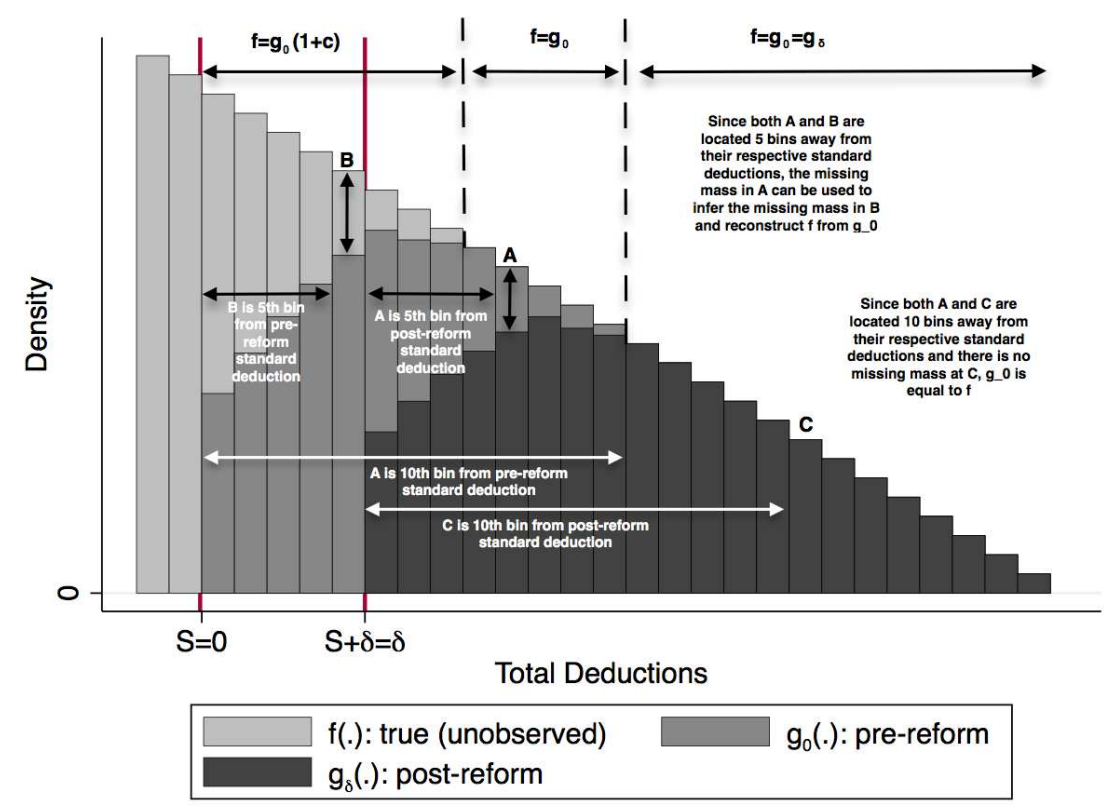

(b) Reconstructed Counterfactual

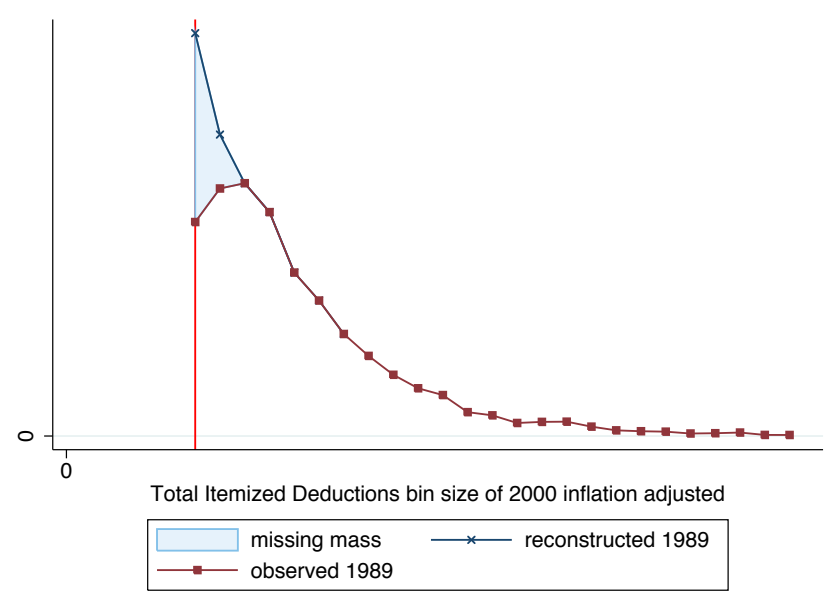

Notes: The first graph illustrates the method used in section 3.1 to reconstruct the counterfactual density of itemizers $f($.$) using the pre- and post-reform densities g_{0}($.$) and g_{\delta}($.$) . The second$ graph plots the reconstructed counterfactual in 1989 using the method outlined in section 3 and the observed density for 1989. The missing mass used to estimate the cost of itemizing is given by the area lying between the two curves. 


\section{Figure 4: Relationship Between Income and the Cost of Itemizing Deductions}

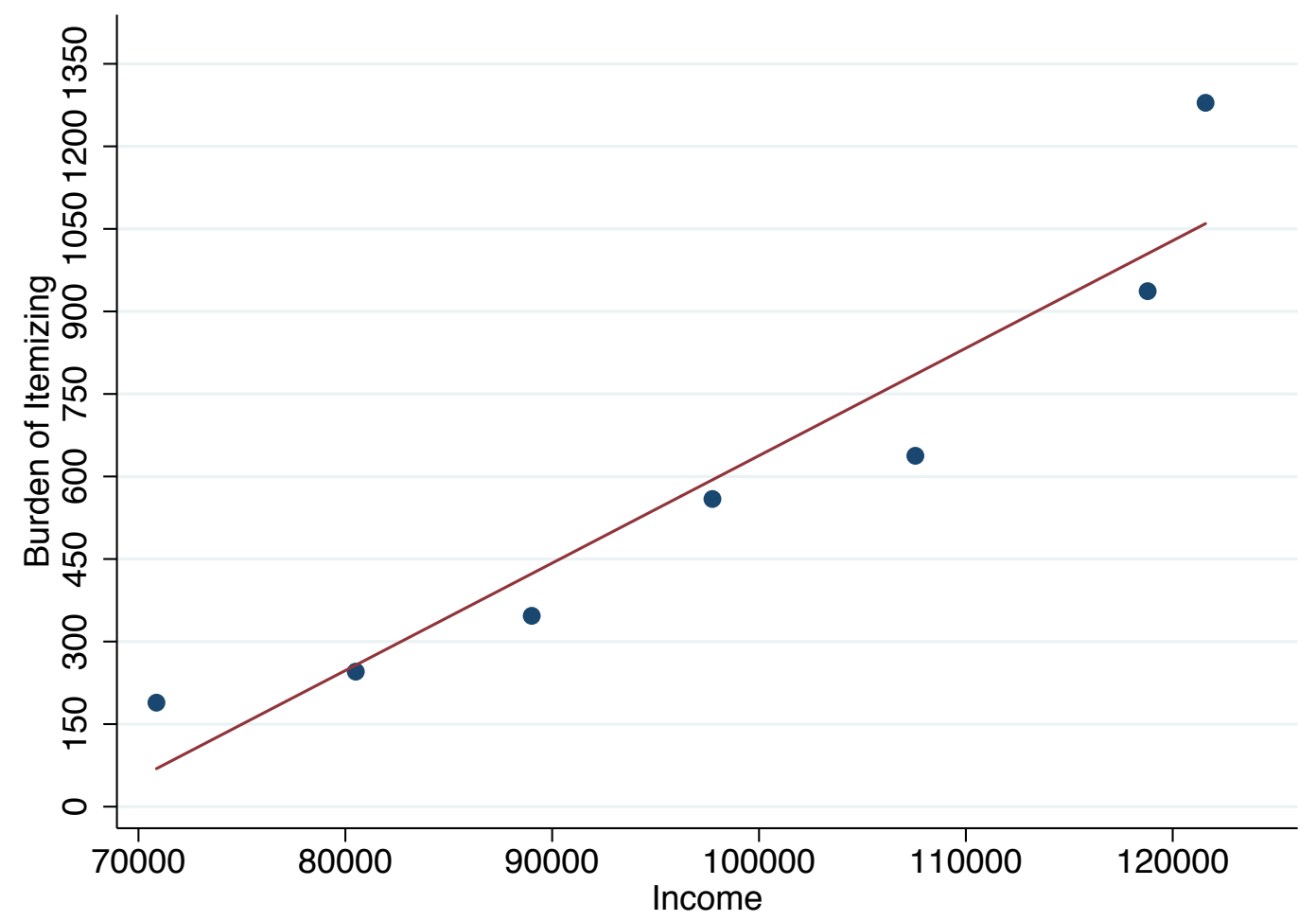

Notes: This graph shows the increasing relationship between income and the cost of itemizing: richer households are more likely to forgo deductions. This relationship controls for the variation in MTR across the different income groups. 


\section{Figure 5: Use of Tax Preparer and Electronic Filing}

(a) Tax Preparer

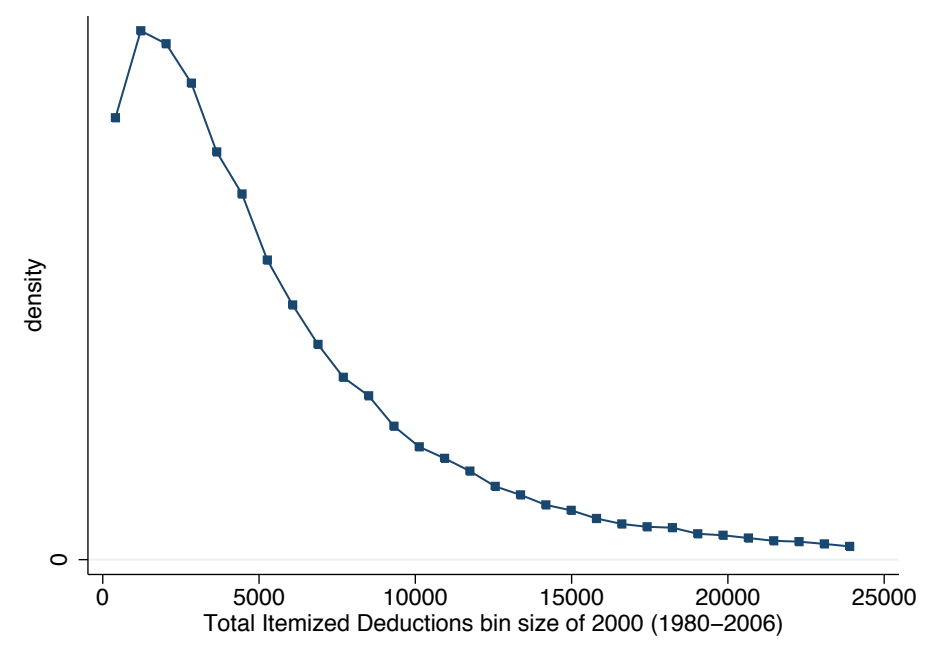

(b) Electronic Filing

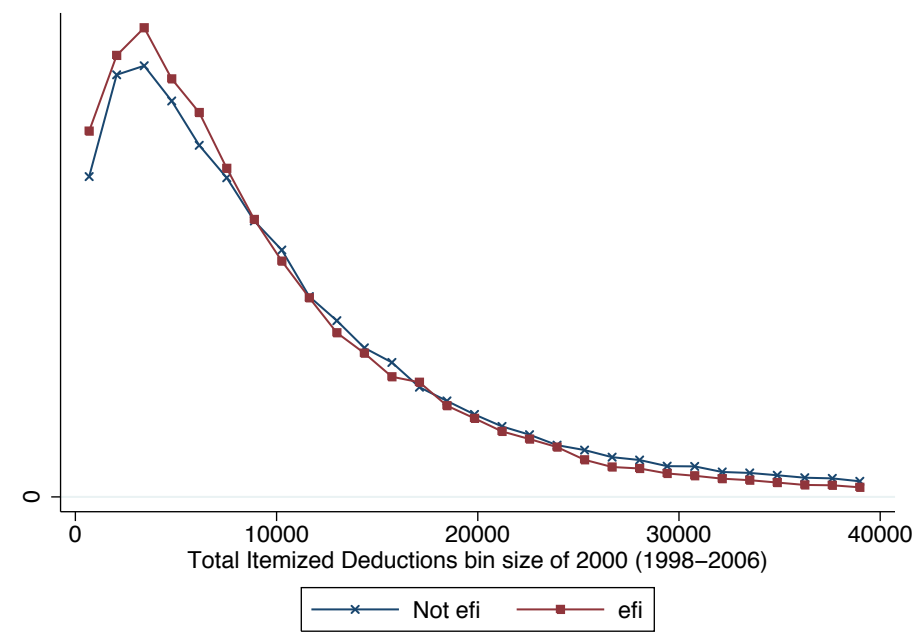

Notes: The x-axis is normalized such that 0 corresponds to the standard deduction threshold. Graph (a) plots the density of total deductions for taxpayers who use tax preparers from 1980 to 2006 by bin size of $\$ 2000$. Graph (b) plots the density of total deductions for taxpayers who file returns electronically from 1998 to 2006 by bin size of $\$ 2000$ and compares it to the density of taxpayers who do not file returns electronically. Both graphs exhibit a missing mass close to the standard deduction implying that neither tax preparers nor electronic filing eliminate the cost of itemizing. The use of electronic filing slightly reduces the missing mass consistent with compliance costs being the driver of the missing mass and record-keeping being the largest portion of the cost of itemizing. 


\section{Figure 6: Concave Kink Point: Densities Following Reform Should Not Overlap}

(a) Concave Kink Point

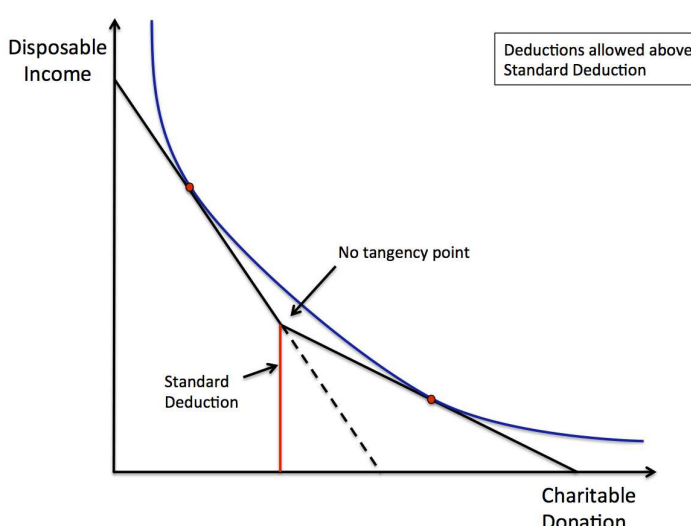

(b) Missing Mass Due to Concave Kink Point

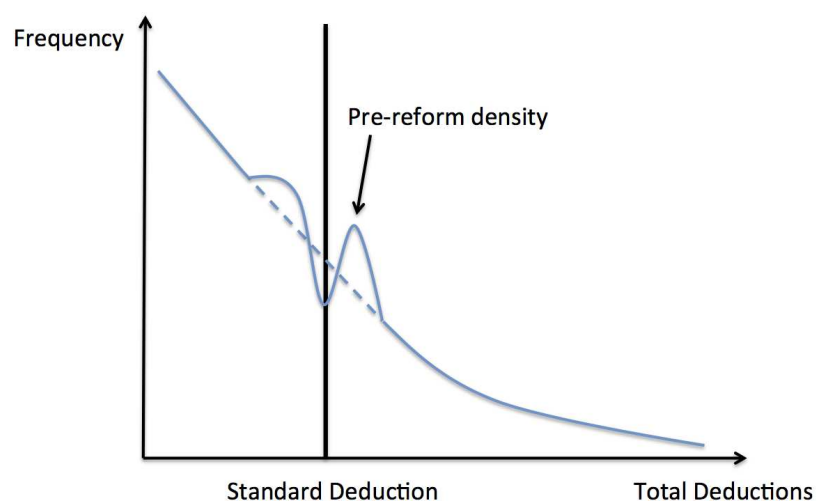

(c) Pre and Post Reform Densities

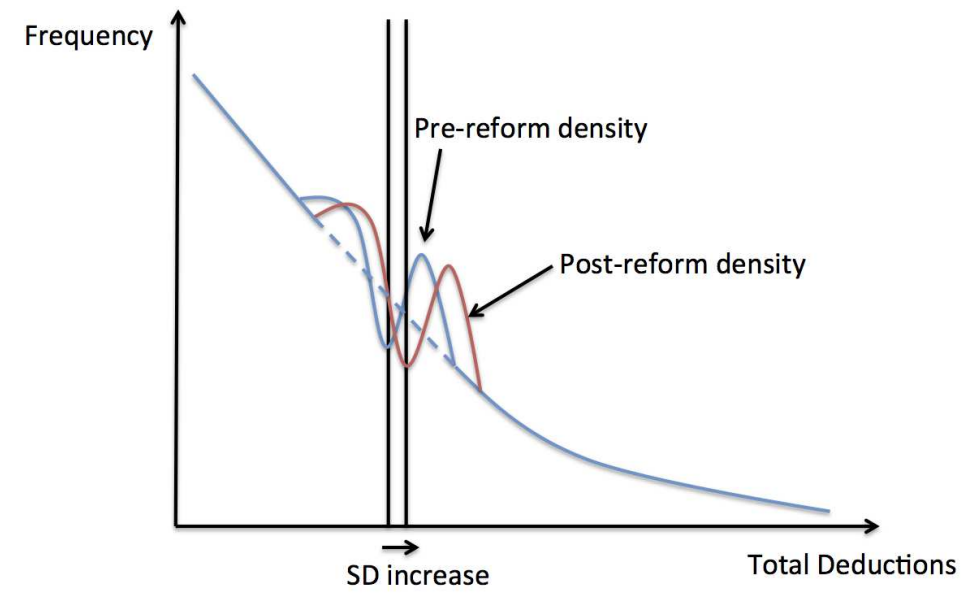

Notes: Panel (a) displays a budget set with a concave kink point. Panel (b) shows the effect that a concave kink point could in theory have on the density of itemizers. Panel (c) shows that if itemizers were responding to the concave kink point, we should observe that the pre and post reform densities are not overlapping just above the standard deduction. This is contradicted by figure 2a. 


\section{Figure 7: Cost Trends}

\section{(a) Total Costs}

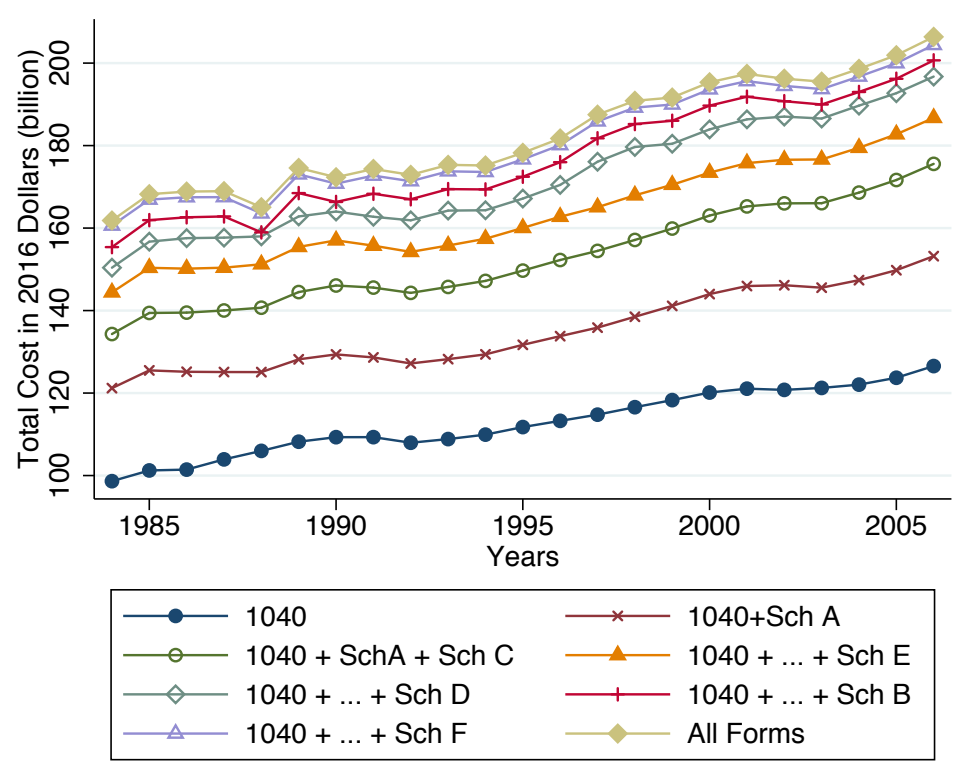

(b) Number of Forms Filed

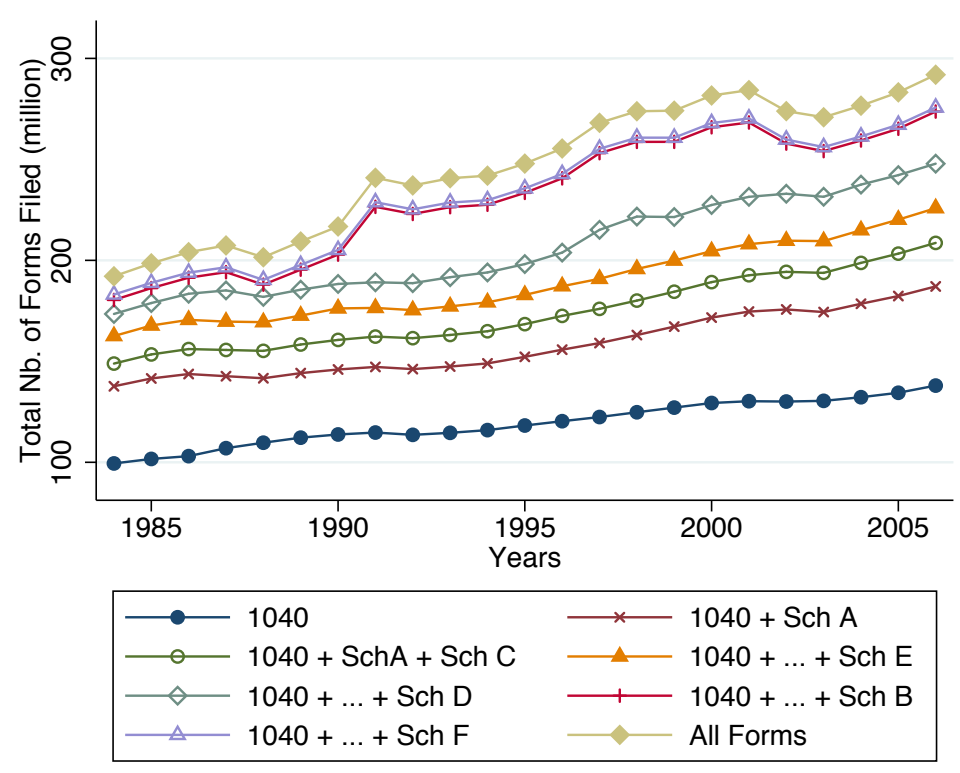

Notes: The first figure plots the cost of filing each schedule for the total US population over time as estimated in equation (7). The second figure plots the total number of forms filed over time. Each curve is cumulative: it incrementally adds each schedule to the previous curve. 
Figure 8: Deadline Effects

(a) Google Search of the Term 1040

(b) Number of Returns Filed by Week
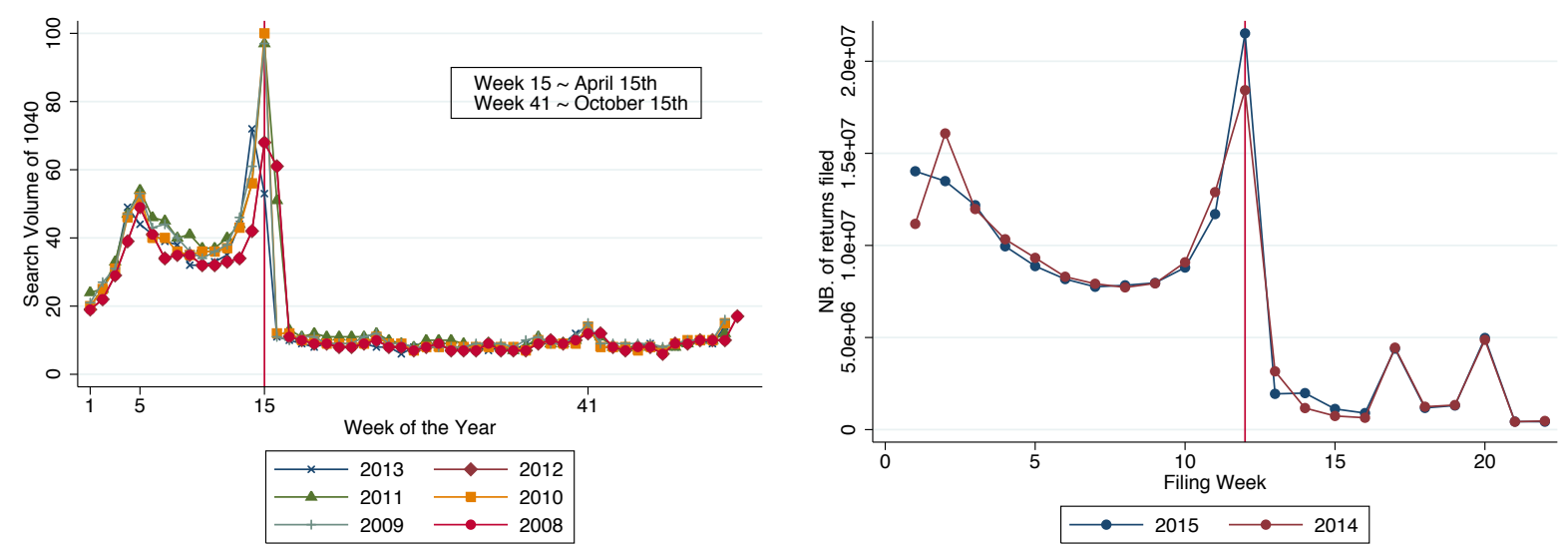

(c) March Itemizers v.s. April Itemizers

(d) Processing Week in Year $t$ v.s. $t-1$
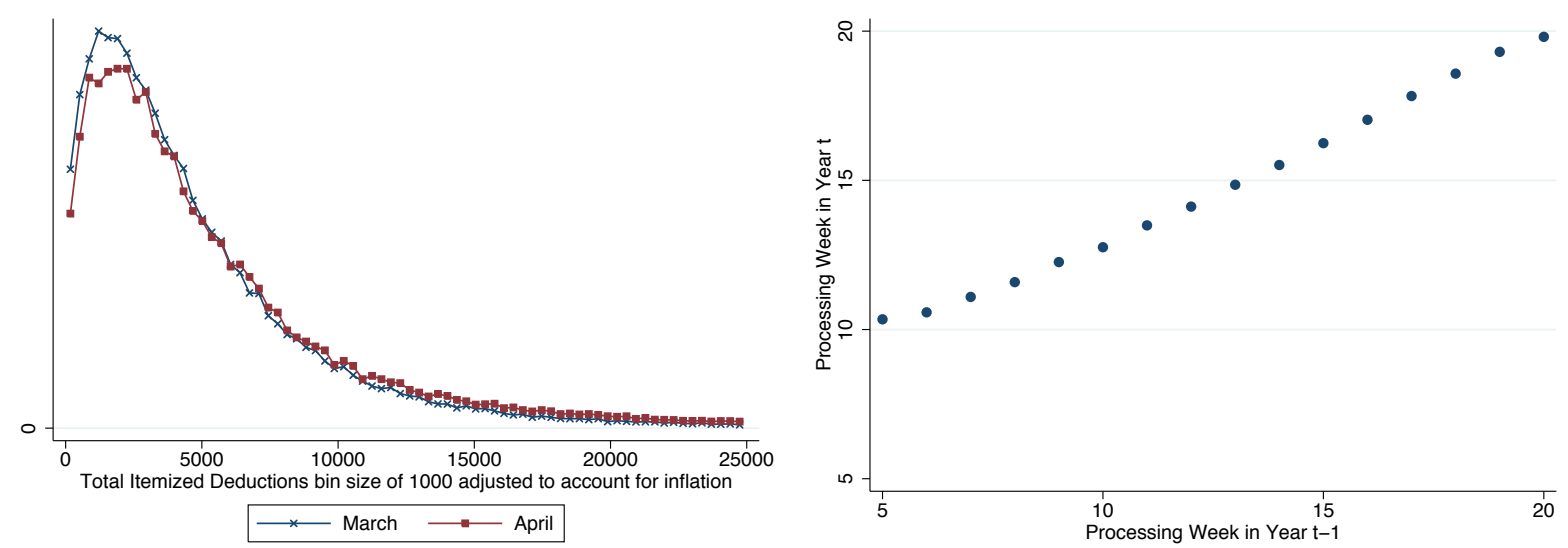

Notes: Panel (a) plots the volume of search of the term "1040" in Google and panel (b) plots the volume of tax returns filed by week in 2014 and 2015. The red vertical line corresponds to the week of April 15. Panel (c) plots the density of itemizers who file in March versus in April, the x-axis is normalized such that 0 corresponds to the standard deduction. Panel (d) plots the average week in which a return is processed in year $t$ on the y-axis and the average week in which a return is processed in year $t-1$ on the $\mathrm{x}$-axis. 


\section{Figure 9: Audit Survey}

(a) Expected Cost of Audit

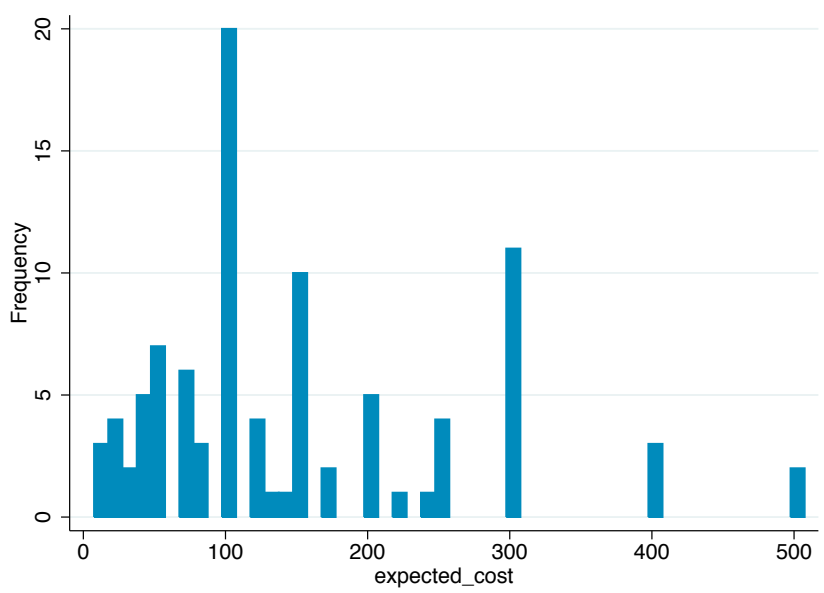

(c) Cost of Audit

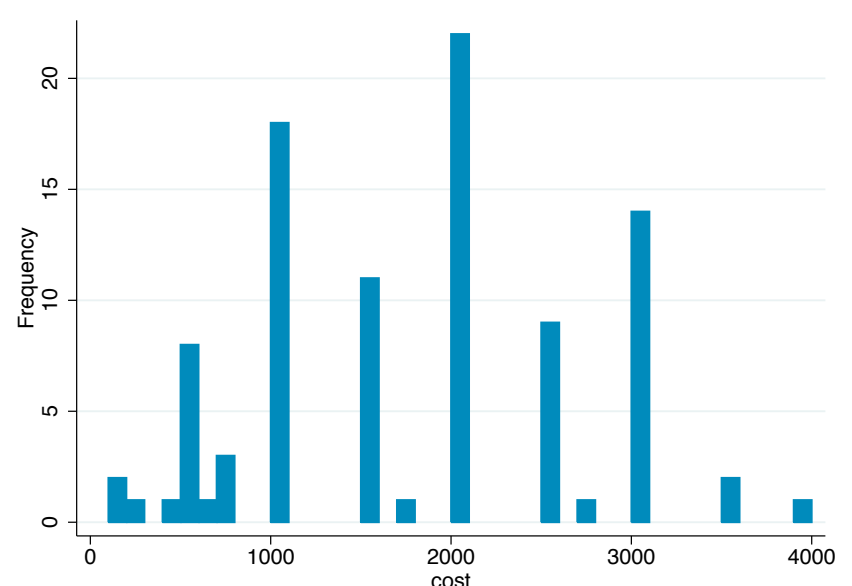

(b) Audit Probability

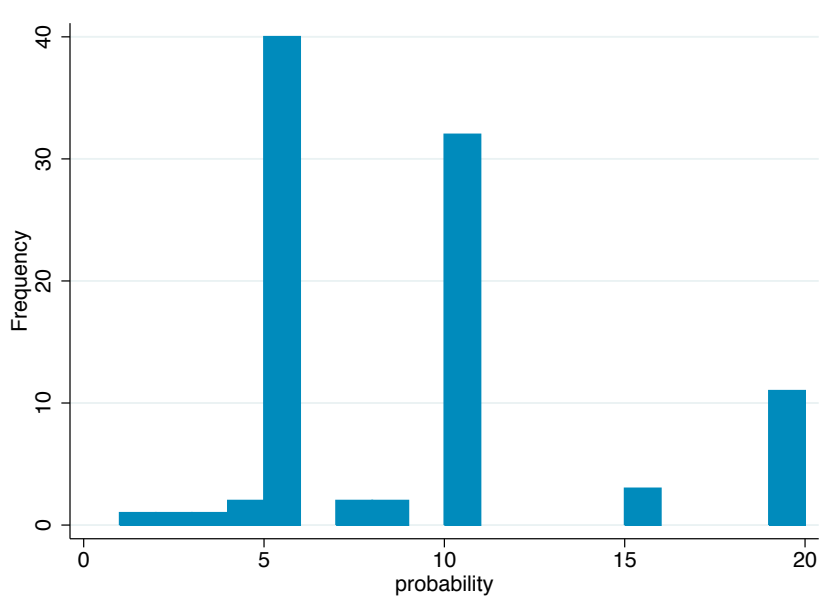

(d) Income (in \$1,000)

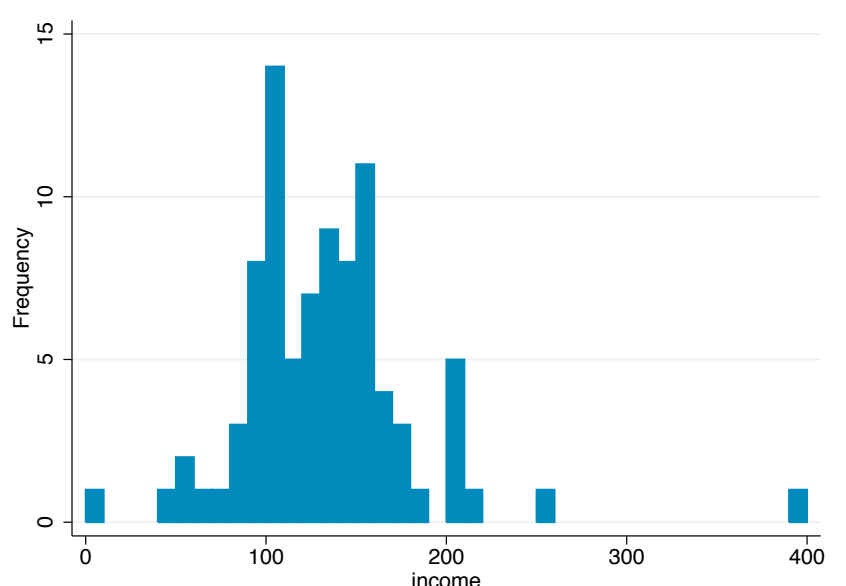

Notes: The number of observations for each panel is 95 individuals. Panel (a) is the distribution of expected cost of audit and is equal to the product of audit probabilities by cost of audit. Panel (b) is the distribution of perceived audit probabilities. Panel (c) is the distribution of cost of audit. Panel (d) is household income in brackets of $\$ 1,000$. 195 individuals were surveyed, of which 95 files their taxes themselves and itemize deductions. 


\section{Table 1: Cost Variables}

\begin{tabular}{|c|c|}
\hline Variable & Cost \\
\hline$\beta_{A}$, Single, $\tau=15 \%$ & $\$ 175$ \\
\hline$\beta_{A}$, Single, $\tau=28 \%$ & $\$ 369$ \\
\hline$\beta_{A}$, Joint, $\tau=15 \%$ & $\$ 195$ \\
\hline$\beta_{A}$, Joint, $\tau=28 \%$ & $\$ 591$ \\
\hline$\beta_{A}$, Head, $\tau=15 \%$ & $\$ 270$ \\
\hline$\beta_{A}$, Head, $\tau=28 \%$ & $\$ 458$ \\
\hline$\beta_{1040}$ & $2.08 \beta_{A}$ \\
\hline$\beta_{B}$ & $0.28 \beta_{A}$ \\
\hline$\beta_{C}$ & $2.13 \beta_{A}$ \\
\hline$\beta_{D}$ & $0.83 \beta_{A}$ \\
\hline$\beta_{E}$ & $1.29 \beta_{A}$ \\
\hline$\beta_{F}$ & $3.55 \beta_{A}$ \\
\hline$\beta_{S E}$ & $0.25 \beta_{A}$ \\
\hline$\alpha \overline{d e p}$ & 0.99 \\
\hline$\alpha_{d e p}$ & 1.01 \\
\hline$\overline{\alpha \overline{e f i}}$ & 1.07 \\
\hline$\alpha_{e f i}$ & 0.93 \\
\hline$\alpha_{\overline{p r e p}}$ & 0.99 \\
\hline$\alpha_{\text {prep }}$ & 1.01 \\
\hline$\alpha_{1}$ & 0.21 \\
\hline$\alpha_{2}$ & 0.21 \\
\hline$\alpha_{3}$ & 0.27 \\
\hline$\alpha_{4}$ & 0.38 \\
\hline$\alpha_{5}$ & 0.61 \\
\hline$\alpha_{6}$ & 0.99 \\
\hline$\alpha_{7}$ & 1.4 \\
\hline$\alpha_{8}$ & 1.74 \\
\hline$\alpha_{9}$ & 2.7 \\
\hline
\end{tabular}

Notes: This table shows the estimates used in equations (6) and (7). $\beta_{A}$ is estimated in section 3.1. $\beta_{1040}, \beta_{B}, \beta_{C}, \beta_{D}, \beta_{E}, \beta_{F}$ and $\beta_{S E}$ are estimated in section 6.2. Section 6.1 explains how $\alpha_{d e p}, \alpha_{e f i}$ and $\alpha_{\text {prep }}$ are estimated. Section 4.1 explains how $\alpha_{i}, i=1, \ldots, 10$ are estimated. 
Table 2: Standard Errors of the Difference Between the 1987 and 1989 Densities (figure 2a)

\begin{tabular}{ccccc}
\hline \hline Bin & $\begin{array}{c}\text { Deduction } \\
\text { Range }\end{array}$ & Difference & $\begin{array}{c}\text { Standard } \\
\text { Errors }\end{array}$ & Z-stat \\
\hline 1 & {$[9991,11991]$} & $0.00311^{* * *}$ & 0.00047 & 6.55 \\
2 & $(11991,13991]$ & $0.00190^{* * *}$ & 0.00044 & 3.47 \\
3 & $(13991,15991]$ & 0.00000 & 0.00040 & 0.02 \\
4 & $(15991,17991]$ & -0.00047 & 0.00041 & -1.13 \\
5 & $(17991,19991]$ & 0.00022 & 0.00038 & 0.59 \\
6 & $(19991,21991]$ & -0.00010 & 0.00033 & -0.31 \\
7 & $(21991,23991]$ & -0.00041 & 0.00028 & -1.45 \\
8 & $(23991,25991]$ & -0.00042 & 0.00025 & -1.67 \\
9 & $(25991,27991]$ & -0.00032 & 0.00020 & -1.60 \\
10 & $(27991,29991]$ & $-0.00042^{* *}$ & 0.00018 & -2.24 \\
\hline \hline
\end{tabular}

Notes: This table shows the bootstrapped standard errors for the difference between bins in figure $2 \mathrm{a} *$ denotes significance at the $10 \%$ level, ${ }^{* *}$ at the $5 \%$ level and ${ }^{* * *}$ at the $1 \%$ level. I use 100 replications for the bootstrap estimation.

\section{Table 3: Calibration of Rational Inattention Model}

\begin{tabular}{ccccccccc}
\hline \hline & \multicolumn{8}{c}{ About Level of Savings $(\sigma)$} \\
& \multicolumn{1}{c}{ Abrion of Beliefs } \\
CRRA coefficient & 10 & 50 & 100 & 200 & 500 & 1000 & 2000 & 3000 \\
\hline 0.1 & 0 & 0 & 0 & 1 & 5 & 28 & 70 & 152 \\
0.25 & 0 & 0 & 0 & 2 & 11 & 44 & 167 & 203 \\
0.5 & 0 & 0 & 1 & 4 & 22 & 86 & 64 & 625 \\
0.8 & 0 & 0 & 1 & 5 & 35 & 134 & 462 & 880 \\
1 & 0 & 1 & 2 & 7 & 44 & 164 & 547 & 1015 \\
1.1 & 0 & 1 & 2 & 8 & 48 & 179 & 586 & 1074 \\
1.25 & 0 & 1 & 2 & 9 & 54 & 200 & 640 & 1153 \\
1.5 & 0 & 1 & 3 & 11 & 64 & 233 & 718 & 1262 \\
1.8 & 0 & 1 & 3 & 13 & 76 & 270 & 799 & 1364 \\
2 & 0 & 1 & 4 & 14 & 84 & 293 & 844 & 1417 \\
\hline \hline
\end{tabular}

Notes: This table shows the results of a calibration of the rational inattention model derived in section 5.4 . 


\section{WEB APPENDIX FOR ONLINE PUBLICATION}

\section{A Pitt and Slemrod (1989)}

Pitt and Slemrod (1989) very elegantly apply the methods of Gronau (1973) and Nelson (1977) to assess the compliance cost of itemizing deductions by estimating a censored model with unobserved censoring thresholds using maximum likelihood.

To do so they estimate a cost and benefit function of itemizing deductions. The benefit of itemizing is given by $T S_{i}=X_{i} \beta+u_{i}$ where $X_{i}$ are exogenous and observed characteristics, $\beta$ is a vector of parameters and $u_{i}$ an error term. Similarly, the cost of itemizing is assumed to be $C_{i}=Z_{i} \gamma+v_{i}$, where $Z_{i}$ are exogenous and observed characteristics, $\gamma$ a vector of parameters and $v_{i}$ an error term. A person will itemize if $T S_{i} \geq C_{i}$. $T S_{i}$ is only observed when $T S_{i} \geq C_{i}$ but $C_{i}$ is never observed. Gronau (1973) and Nelson (1977) show that if $u_{i}$ and $v_{i}$ are uncorrelated or if there are some characteristics present in $X_{i}$ but not in $Z_{i}$ then the model is identified and a likelihood function can be maximized to estimate both $T S_{i}$ and $C_{i}$. Pitt and Slemrod (1989) acknowledge that there is no reason to assume that the errors are uncorrelated but that there are some characteristics that are likely to be present in $X_{i}$ but not in $Z_{i}$, therefore arguing that identification should be valid.

The set of exogenous and observable characteristics they consider to estimate both $\beta$ and $\gamma$ are whether a person is married, her AGI, the square of AGI, whether a person owns a farming business, the number of age exemptions a person claims and the number of exemptions claimed. The set of exogenous characteristics specific to $\beta$ are positive investment income, the average state income and sales taxes for an income of $\$ 40,000$, the average property tax rate in a given state and an index of medical costs in a given state.

If the assumptions from Gronau (1973) and Nelson (1977) hold and given these exogenous and observed characteristics, they can estimate the cost and benefit function. They find that the average cost of itemizing is $\$ 107$ (in 2016 dollars) i.e. 6 times lower than the cost I estimate. 
Since Pitt and Slemrod (1989) acknowledge that $u_{i}$ and $v_{i}$ are likely to be correlated, for the Gronau (1973) and Nelson (1977) estimators to be consistent, the exclusion restriction imposed on $X_{i}$ and $Z_{i}$ becomes necessary for identification.

\section{B Assumption A2}

Assumption A2 states that the cost should not increase with the level of deductions. It makes sense to assume that the cost of deducting $\$ 10,000$ worth of mortgage interest is the same as deducting $\$ 100,000$ because total mortgage interest is reported on form 1098. However, it is also reasonable to assume that an individual who donates $\$ 100,000$ to charity is more likely to donate to more charities than an individual who donates $\$ 10,000$.

Assumption A2 is important for equation 3. Intuitively, it allows me to infer the distortion imposed by the standard deduction on the pre-reform distribution in bin $j$ from bin $j+m$ when the pre- and post-reform standard deduction thresholds are $m$ bins away. A2 can fail if the cost of itemizing decreases with the size of total deductions which would bias my cost estimate downwards. But more importantly it can fail if the cost of itemizing increases with the size of total deductions, which would overestimate the cost. There is an easy way to provide an upper bound for the bias introduced by a failure of A2: by using the pre-reform distribution $g_{\delta}(d)$ as the true counterfactual instead of $f(d)$. This is a generous upper bound because it assumes that the pre-reform distribution is undistorted just above the standard deduction in spite of figure 2 a showing a clear distortion. In this case, the estimated cost would be $\$ 519$ instead of $\$ 591$. Therefore if A2 fails, the cost of itemizing would lie between $\$ 519$ and $\$ 591$.

\section{Sample Restrictions}

\section{C.1 Figure 1}

The sample used for figure 1 are joint filers who itemize deductions. I focus on joint filers because they represent more than $50 \%$ of the population and the standard deduction is specific to the filing status. This means that I cannot show every tax filing status on the same graph because they would have different standard deductions. Figure H.15 shows the same patterns for single taxpayers. 


\section{C.2 Figures 2a, 2b}

In figure $2 \mathrm{a}$ and $2 \mathrm{~b}$, I focus on taxpayers who are married filing jointly for the reasons outlined in section C.1. In addition, in 1988 and 1989 there were two tax brackets (15\% and 28\%) and a tax rate "bubble" (33\%). Most taxpayers who itemize deductions fall in the $28 \%$ marginal tax bracket. Therefore, to control for the change in marginal tax rates, I only consider taxpayers who fall in the $28 \%$ marginal tax rate bracket. This allows me to precisely calculate the amount of after tax forgone benefit.

\section{C.3 Figure 4}

In figure 4, I use the same sample restrictions as in figure $2 \mathrm{a}$ and $2 \mathrm{~b}$ and break down the sample into deciles of income.

\section{C.4 Figure 5}

To generate figure 5, I consider joint filers as explained in section C.1. In figure (a), I consider all years from 1980 to 2006 but exclude 1985 and 1990 because the tax preparer variable is missing in those years. In figure (b), I consider all years from 1998 to 2006 because few taxpayers used electronic filing prior to 2006.

\section{C.5 Figure 8c}

The variable indicating the week in which a return is processed by the IRS is only present in the SOI files in year 1980 to 1999. Thus, to generate figure $8 \mathrm{c}$, I restrict attention to those years. I use the same sample restrictions as in figure C.1 in addition to dropping taxpayers who have a balance due to the IRS. If taxpayers owe money to the IRS, it is rational to wait as much as possible so as to save on interest.

\section{C.6 Week of Filing Variable}

The SOI files contain a variable that indicates the week in which a return is processed by the IRS. Slemrod et al. (1997) have access to the internal IRS files that record the filing date and compare it to the processing date from the SOI files. They find that the order in which returns are processed matches the order in which they are filed. Knowing the order is sufficient for my purposes because what I am interested in is comparing taxpayers who file close to the deadline to those who file earlier. I can therefore use the processing time variable to identify late filers and verify the predictions of the naive present bias model. The IRS 
promises that returns are processed within 6 weeks. This constraint is likely to be binding for returns that are filed close to the deadline given that a lot of returns are processed at the time. Therefore, I assume that the processing time has a lag of 6 weeks.

I restrict the sample used to generate this graph to taxpayers who are owed refunds by the IRS and who do not have to file any other schedule but Schedule A. This allows me to rule out taxpayers who rationally delay filing to save on interest on the amount they owe to the IRS and taxpayers who cannot file early because others schedules sometimes require additional paperwork that only becomes available later in the year.

\section{C.7 Taxpayers Who Have To Claim the Standard Deduc- tion}

In rare cases, taxpayers have to claim the standard deduction even when their itemized deductions exceed the standard deduction. These individuals are dropped from my sample. This happens in the following four cases:

1. A married taxpayer whose spouse files separately and itemizes deduction.

2. In some states, a taxpayer who wants to itemize on her state tax return has to itemize on her federal tax return as well.

3. A taxpayer who is neither a citizen nor a permanent resident of the United States.

4. A taxpayer who can benefit from itemizing for alternative minimum tax purposes even though the standard deduction is greater than the sum of her itemized deductions.

\section{Tax Reform Act of 1986 and Lagged Responses}

Could there be any other exogenous variation altering the distribution of itemized deductions in 1989 affecting my main identification strategy? The majority of tax reforms happened following the TRA'86 and were enacted in 1987. Among those, there were some deduction reforms. Because I am comparing 1987 to 1989, I am implicitly controlling for the Tax Reform Act of 1986 (TRA'86) reforms. But there might be slow adjustments and lagged responses in 1988 or 1989. To rule these out, I consider all the reforms enacted by TRA' 86 that could affect the level of deductions and show that it is reasonable to assume that the adjust- 
ment is immediate. Because all of the reforms reduced the amount of eligible deductions, they have no lagged response. To see this consider a hypothetical example: assume the charitable donation deduction is capped at $\$ 10,000$. A taxpayer who was donating $\$ 15,000$ will now only be able to deduct $\$ 10,000$. Will the taxpayer reduce her donations? She might reduce them up to $\$ 10,000$ but there is no reason to expect that she will reduce them any further. What does this imply for the level of deductions? We should observe a drop in deductions to $\$ 10,000$ in 1987 and then no further drop in 1988 or 1989, ruling out any lagged responses. Since I am comparing 1987 to 1989, any reform that caps the amount of deductions should not affect my estimates. The deduction reforms enacted in 1987 are the following (source: IRS):

- Prior to 1987, medical deductions in excess of $5 \%$ of the AGI are deductible. In 1987, this threshold is increased to $7.5 \%$ of AGI, further limiting the allowable amount of medical deductions. There is no reason to assume that there will be a slow adjustment that spills over into 1988 or 1989 in this case.

- Sales taxes are not deductible anymore. For similar reasons, one should observe a drop in the total deductions in 1987 as sales taxes were a large portion of it but there should be no lagged effect.

- The home mortgage interest deduction is subject to a new limit. The home mortgage interest deductions for a given year are capped at the value of one's house (plus renovations). Anything in excess of the value of the house have to be deducted as personal interest for which only $65 \%$ of the total value can be deducted. First, the IRS estimated that very few taxpayers were affected by this reform since it is very rare that one's home mortgage interest in one given year exceeds the total value of one's house. Second, there is no reason to expect a drop in levels in the subsequent years. If a person is affected by this reform, in 1987 she will be forced to claim less deduction than she was previously claiming.

- Any interest for home mortgages in excess of 1 million dollars is not deductible anymore. Again, there is no reason to expect any lagged effects due to this reform because it caps the amount of deductions.

There are no other reforms affecting directly or indirectly the amount of item- 
ized deductions an individual can qualify for.

\section{E The 1971, 1975 and 2003 reforms}

\section{E.1 The 1971 and 1975 reforms}

In 1970 and 1975 taxpayers could claim as a standard deduction the smaller of the standard deduction or $10 \%$ of their income. In 1971, both thresholds were increased to $\$ 8,809$ or $13 \%$ of income if income is greater than $\$ 46,983$, and the larger of $\$ 6,166$ or $13 \%$ of income for taxpayers with income smaller than $\$ 46,983$. In 1975, a similar two tiered standard deduction existed with an AGI limit of 16\% and a dollar limit of $\$ 74,431$.

If I were to only look at the density of itemizers above $\$ 6,130$ in 1970 and compare it to the density of itemizers above $\$ 8,809$ in 1971 , my estimates would be biased because some taxpayers who have deductions greater than $\$ 8,809$ in 1971 are likely to stop itemizing - not because of compliance costs - but only because their deductions are now smaller than $13 \%$ of their income. This is why using 1971 and 1975 will not yield accurate estimate of compliance costs (they tend to over-estimate them).

\section{E.2 The 2003 reform}

Two main changes occurred in 2003 that affect the post-reform standard deduction. The first one is that tax rates were reduced 2 to 3 percentage points (depending on the bracket), reducing the incentive to itemize. The second one is that electronic filing was rapidly expanding in the early 2000's complicating the comparison between the pre and post-reform standard deduction.

\section{F Audit Survey}

The survey was carried outside a health food supermarket in Santa Monica, California. The location was chosen to attract as many wealthy individuals as possible to increase the proportion of itemizers. 195 individuals were surveyed of which 114 file their taxes themselves. Of those 95 itemize deductions, which constitutes the final sample. They were asked the following questions:

1. Do you file taxes yourself?

2. Do you itemize deductions or claim the standard deduction? 
3. Per year, what do you think the chances of being audited are?

4. Assume the IRS wants to audit you. What is the highest amount you would pay a lawyer that would deal directly with the IRS and prevent you from being audited?

5. What is the annual income of your household? (Brackets of $\$ 1,000$ )

\section{G Rational Inattention}

Could taxpayers forgo large amounts of deductions because they are uncertain of whether their total deductions are larger than the standard deductions threshold?

Most of the deductions are relatively stable from year to year as they mostly consist of items that vary very little such as mortgage payments, real estate taxes or state income taxes. This means that taxpayers should have an accurate signal of their true deductions. In addition, the expenses associated with deductions are an active decision: if deductions increase or decrease by a large percentage, taxpayers are likely to be aware of this change because they caused it.

Therefore, for rational inattention to explain the magnitude of the estimated compliance costs, one would need to assume that taxpayers receive a very noisy signal which is unlikely given that deductions vary little from year to year. I formalize this argument in what follows:

Assume that the taxpayer has a Constant Relative Risk Aversion (CRRA) utility function given by $U(x)=\frac{1}{1-\theta} x^{1-\theta}$ if $\theta \neq 1$ and $U(x)=\log (x)$ if $\theta=1$.

Denote by $\tau$ the after tax amount of deductions the taxpayer can claim (deduction multiplied by marginal tax rate) and by $S$ the after tax amount of the standard deduction. Assume that the taxpayer has beliefs over $\tau$ that follow a normal distribution with mean $\mu$ and standard deviation $\sigma$. Denote by $c$ the cost incurred by the taxpayer to calculate the total amount of deductions $\tau$. The cost is only incurred when she itemizes, not when she claims the standard deduction.

The taxpayer will decide to itemize if the expected benefit from itemizing given her beliefs over $\tau$ exceeds the cost of figuring out the level of $\tau$ 1.e. $c$. This occurs 
when the following equation is satisfied:

$$
\mathbb{E}\left[\frac{1}{1-\theta}(\tau-c)^{1-\theta}\right] \geq \frac{1}{1-\theta} S^{1-\theta} .
$$

This equation does not have a closed form solution, so I use a Taylor expansion of second degree around the mean of $\tau-c$, as follows:

$$
\frac{1}{1-\theta}(\mu-c)^{1-\theta}-\frac{1}{2} \theta(\mu-c)^{-1-\theta} \sigma^{2} \geq \frac{1}{1-\theta} S^{1-\theta}
$$

And for $\theta=1$, it is equal to:

$$
\log (\mu-c)-\frac{\sigma^{2}}{2(\mu-c)^{2}} \geq \log (S)
$$

The first term in equation 10 is the expected benefit that the taxpayer derives from itemizing. The second term is a correction for the risk aversion of the taxpayer: she will itemize deductions if the benefit of itemizing corrected for her risk aversion is greater than the benefit she derives from itemizing. Holt and Laury (2002) find a $\theta$ that ranges between -0.95 and 1.37. I assume here that $\theta=1$ but also consider $0<\theta \leq 2^{36}$ in table 3 . I fix the standard deduction at $\$ 10,000$ for joint filers. The cost estimated by the IRS of the time required to itemize deductions is $c=149$. I can calculate a lower bound on the standard deviation of the taxpayer's beliefs over $\tau(\sigma)$. Using these parameters, I find that for rational inattention to explain the magnitude of the forgone benefits, the standard deviation of after tax deductions $\sigma$ has to be greater than $\$ 1,814$ (which corresponds to $\$ 6,479$ worth of deductions with a $28 \%$ marginal tax rate). This means that the taxpayer has a range of uncertainty of deductions of more than $\$ 6,479$. This implies very high uncertainty in the beliefs of the benefits that the taxpayer can save from itemizing which is unlikely given that deductions are relatively stable from year to year as they are mostly constituted of mortgage payments and state taxes and are the results of active decisions. If a taxpayer's total deductions were to increase or decrease dramatically, she would most likely know about it because it would be due to for example to large income variations, the take up

\footnotetext{
${ }^{36}$ Negative values of $\theta$ are not considered because they imply risk lovingness and would trivially reject rational inattention.
} 
of a mortgage etc. which are salient.

If I assume a standard deviation of $\sigma=200$ - which corresponds to a standard deviation of deductions of $\$ 714$ - then rational inattention with $\theta=1$ predicts that taxpayers would claim the standard deduction up to total deductions of $\$ 10,557$ and forgo an average of $\$ 557$ worth of deductions, i.e. 156 of after tax dollars given a cost $\mathrm{c}=\$ 149$. With reasonable parameters, rational inattention predicts that taxpayers will forgo an additional $\$ 7$ in excess of the cost of $\$ 149$.

\section{H Time Inconsistency: Model}

I assume that the cost of record keeping continuously increases for every day that the receipt is not archived as soon as it is received. When the taxpayer is issued a receipt for a charitable donation and fails to archive it, the cost of keeping track of this receipt increases continuously because it is more likely to be lost or it could take more time to look for it. The rational taxpayer archives the receipt as soon it is issued. The naive present-biased taxpayer plans on archiving the receipt but fails to do so, leading to high record keeping costs.

Assume for simplicity that the taxpayer only needs to itemize one deduction for example for a charitable contribution she made. The taxpayer is facing two distinct costs when considering the decision to itemize deductions. The first one is that of record keeping, denoted here by $c$. The second one is filling out Schedule A itself which is denoted by $k$.

If the taxpayer succeeds in performing the two tasks she receives a one time benefit $b$ in the subsequent period. Once the taxpayer gets the receipt for her charitable contribution, she can decide to archive it immediately by incurring a cost $c$ or archive it later and incur a larger cost $c(1+r)$ next period where $r$ is the rate at which the cost of record keeping grows if the receipt is not archived.

$\delta$ is the time-discount factor, $\beta$ the present-bias parameter, $t$ the period in which the record keeping is performed and Schedule $\mathrm{A}$ is filled out and $(t+1)$ the period in benefit $b$ is received.

In what follows, I use two definitions:

Definition 1: For given $\beta, \delta, c, k,(1+r)$ and $t$ a task is said to be $\beta$ worthwhile if $-c(1+r)^{t}-k+\beta b>0$.

Similarly:

Definition 2 For given $\delta, c, k,(1+r)$, and $t$ a task is said to be $\delta$-worthwhile 
if $-c(1+r)^{t}-k+\delta b>0$.

The rational taxpayer has a standard utility function where per-period utility is discounted by $\delta$ in the future.

The decision to itemize or claim the standard deduction for the rational taxpayer can be written as follows:

$$
\max _{t} \delta^{t}\left(-c(1+r)^{t}-k+\delta b\right)
$$

conditional on itemizing being $\delta$-worthwhile.

Cost $c$ is incurred as soon as the taxpayer starts the record keeping. If she waits an additional $t$ periods before archiving the receipt, the cost of record keeping is multiplied by $(1+r)$ for every additional period i.e. $(1+r)^{t}$ overall. Therefore, to minimize the cost of record keeping, the rational taxpayer will choose $t=0$, this means that she will archive the receipt as soon as it is received and will incur a record keeping cost of $c$ rather than $c(1+r)^{t}$.

The taxpayer is left with choosing t such that:

$$
\max _{t} \delta^{t}\left(-c(1+r)^{t}-k+\delta b\right)
$$

Assume the taxpayer is contemplating the decision to perform the record keeping task in the first period yielding utility: $-c-k+\delta b$. She will only perform it if $-c-k+\delta b>0$. And if she waits an additional period she will receive $\delta(-c(1+r)-k+\delta b)$, which is smaller than the utility she would have enjoyed if the task had been performed in the first period. This means that the rational taxpayer will either archive the receipt immediately or never archive it because she does not plan on itemizing her deductions.

The naive present biased taxpayer can perform the record keeping in period $t$ or can wait and perform it in period $t+1$. She will prefer performing it in period $t+1$ if the following inequality is satisfied:

$$
-c(1+r)^{t}-k+\beta b<\beta\left[-c(1+r)^{t+1}-k+b\right] .
$$


This inequality simplifies to:

$$
-c(1+r)^{t}-k<\beta\left[-c(1+r)^{t+1}-k\right]
$$

A sufficient condition for equation 11 to hold is:

$$
(1+r) \beta<1
$$

Intuitively, for the naive present-biased taxpayer to procrastinate on archiving her receipt, it is sufficient that the rate at which the record keeping cost increases be smaller than the rate at which she discounts the future.

Provided that condition 11 holds in period $t=0$, it will also hold in any subsequent period $t>0$ i.e. if itemizing is worthwhile but not performed in the very first period, the taxpayer will procrastinate until she reaches the deadline.

Testable Prediction 1: Naive present-biased taxpayers will file their returns at the deadline of April 15th when condition 11 holds.

Testable Prediction 2: The cost of record keeping for naive present-biased taxpayers is greater than for rational ones. This predicts that taxpayers who file close to the deadline are likely to forgo more deductions. 
Figure H.10: Missing Mass Just Above the Standard Deduction 2004-2006 (Joint Filers)

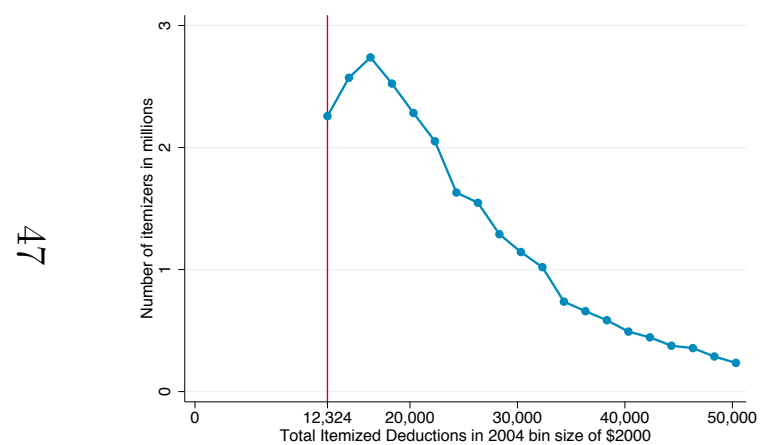

(a) 2004

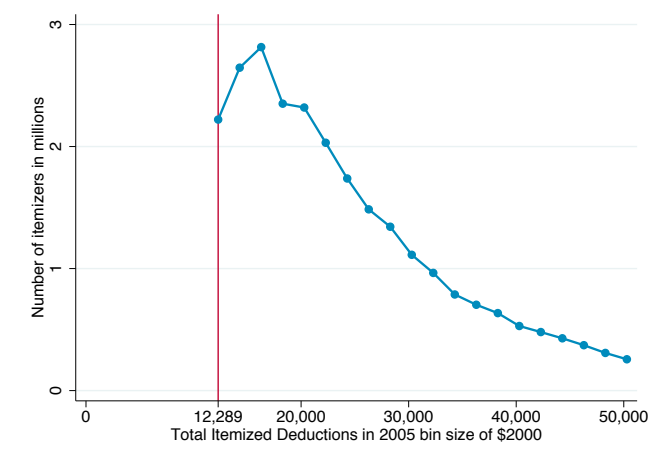

(b) 2005

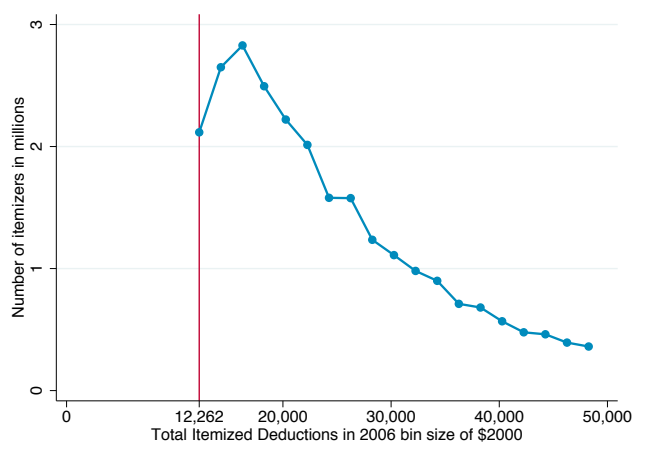

(c) 2006

Notes: The figures above plot the density of deductions for itemizers filing jointly. The bin size is $\$ 2,000$ and the vertical line represents the standard deduction threshold for each year. 
Figure H.11: Missing Mass Just Above the Standard Deduction 1998-2003 (Joint Filers)

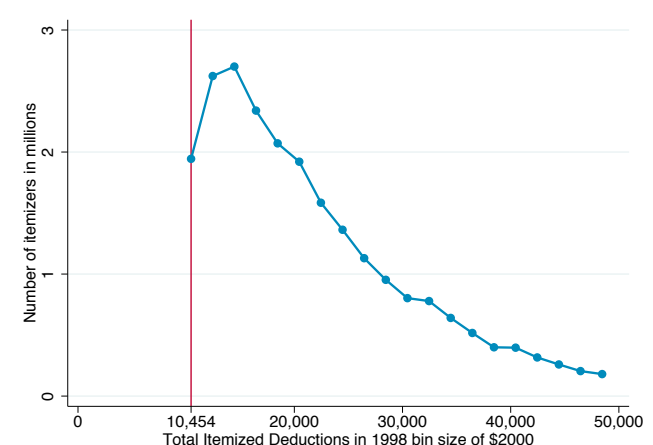

(a) 1998

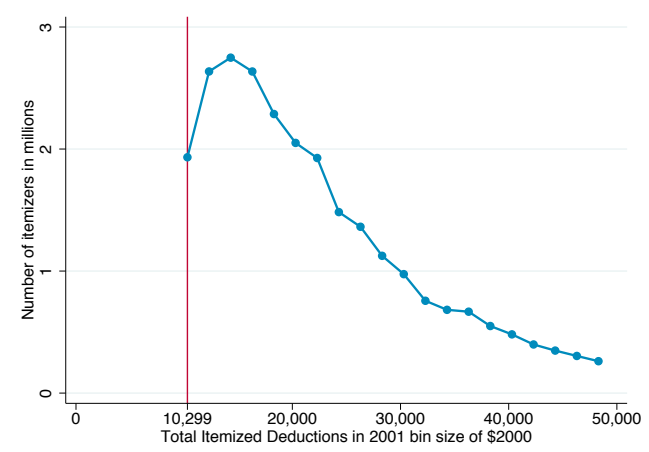

(d) 2001

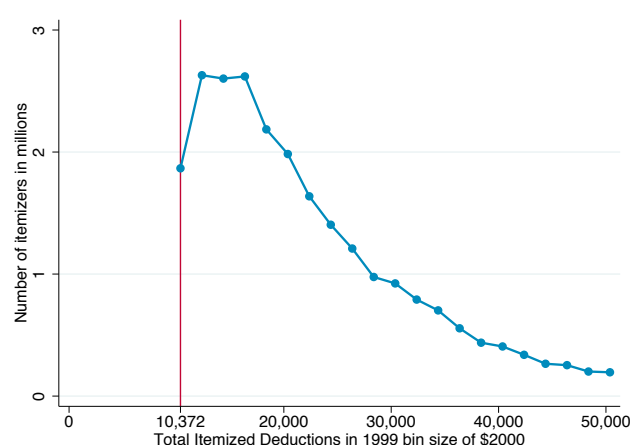

(b) 1999

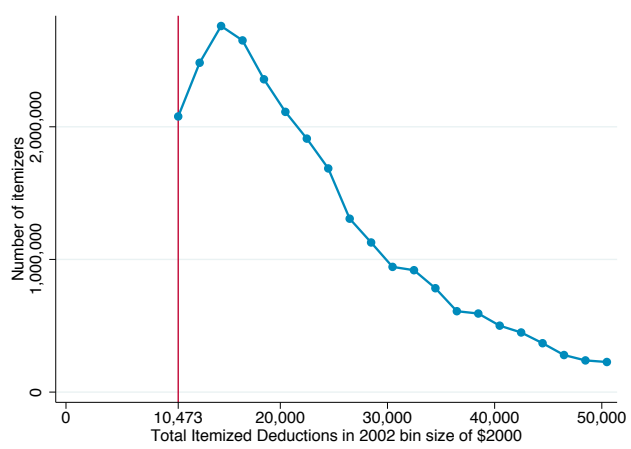

(e) 2002

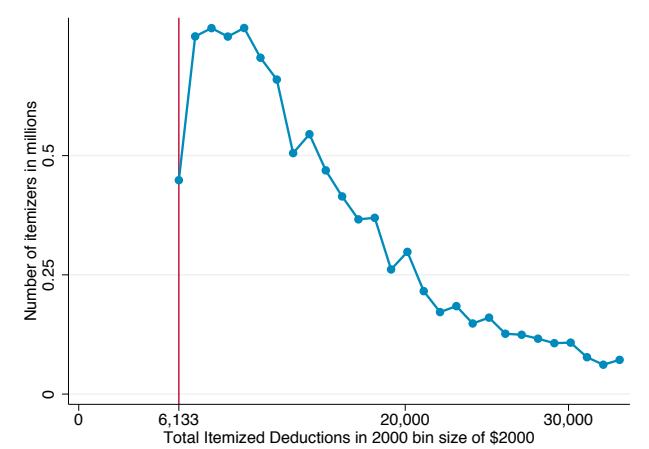

(c) 2000

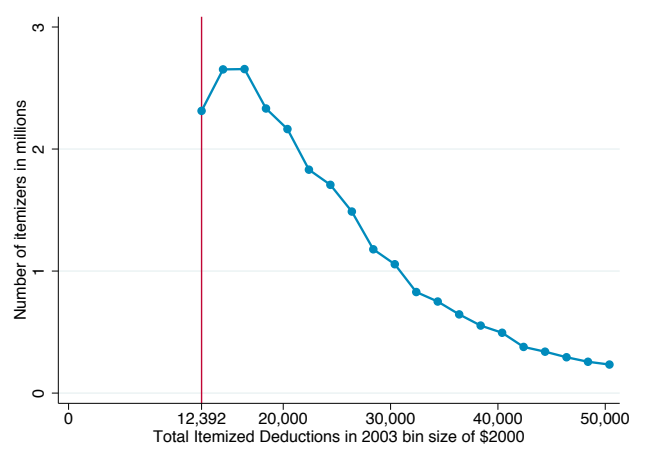

(f) 2003

Notes: The figures above plot the density of deductions for itemizers filing jointly. The bin size is $\$ 2,000$ and the vertical line represents the standard deduction threshold for each year. 
Figure H.12: Missing Mass Just Above the Standard Deduction 1992-1997 (Joint Filers)

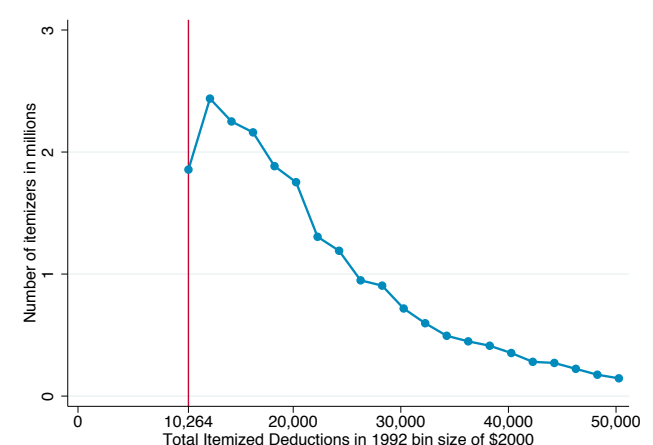

(a) 1992

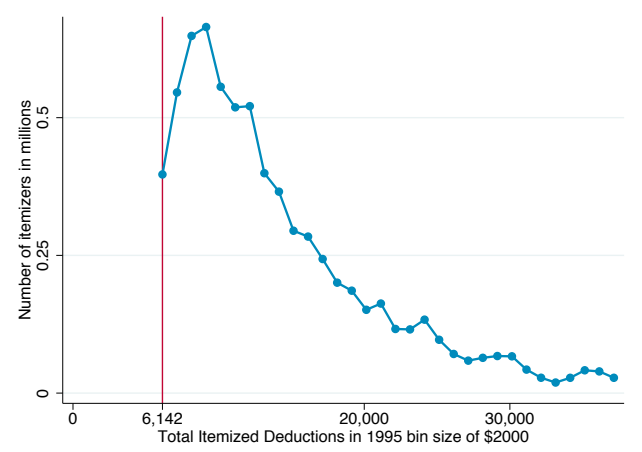

(d) 1995

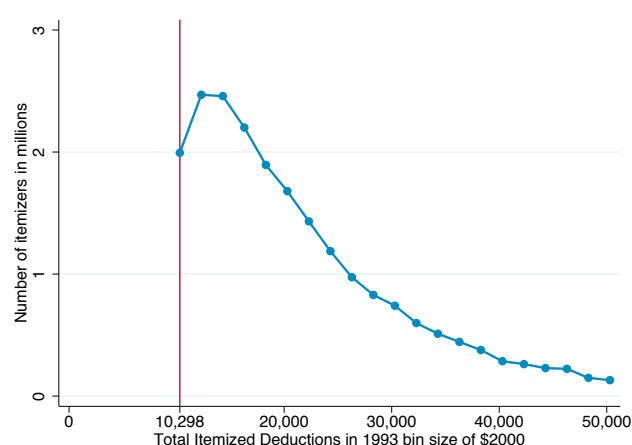

(b) 1993

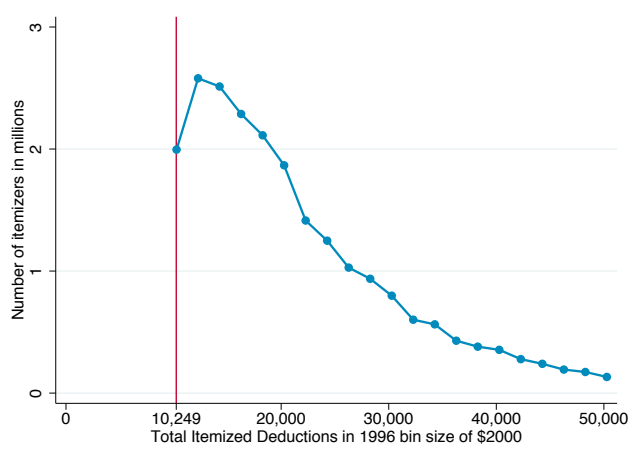

(e) 1996

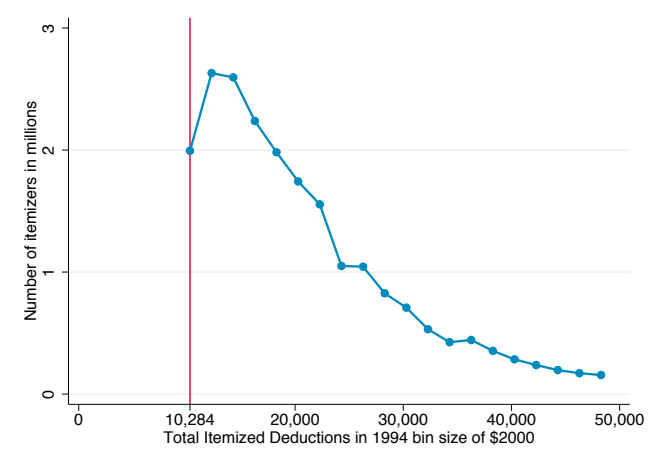

(c) 1994
它

Notes: The figures above plot the density of deductions for itemizers filing jointly. The bin size is $\$ 2,000$ and the vertical line represents the standard deduction threshold for each year.

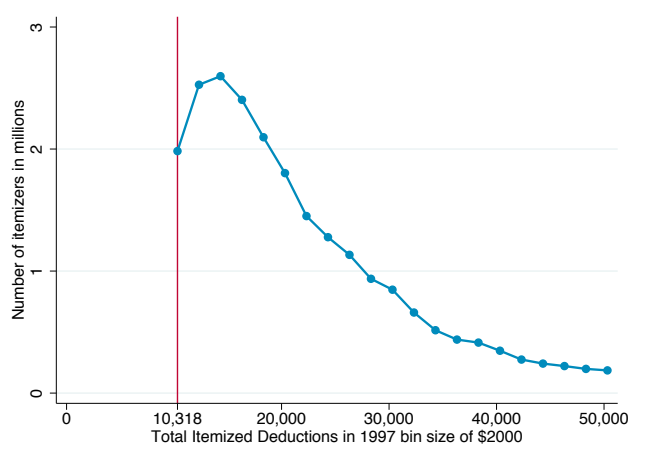

(f) 1997 
Figure H.13: Missing Mass Just Above the Standard Deduction 1986-1991 (Joint Filers)

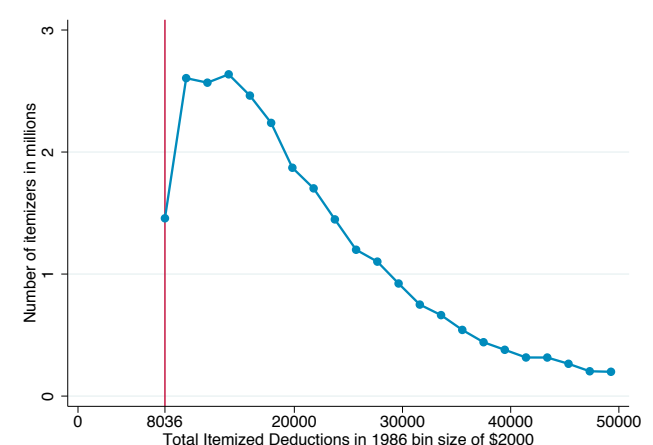

(a) 1986

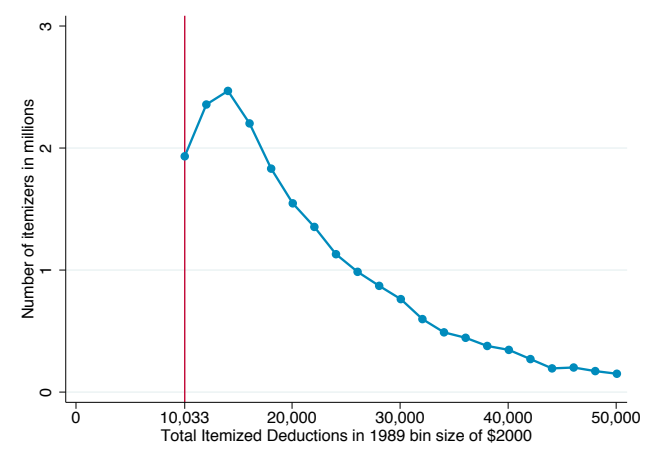

(d) 1989

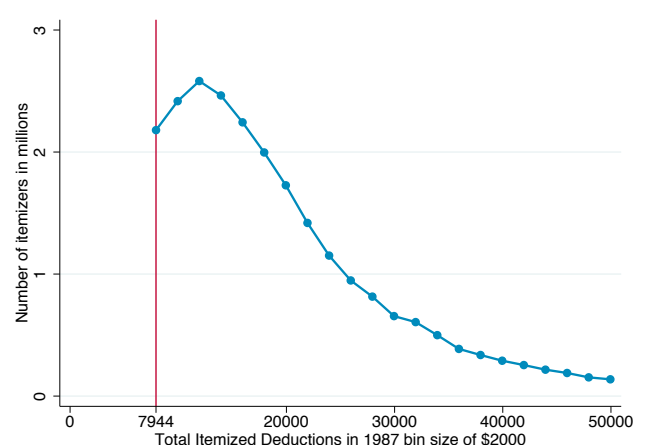

(b) 1987

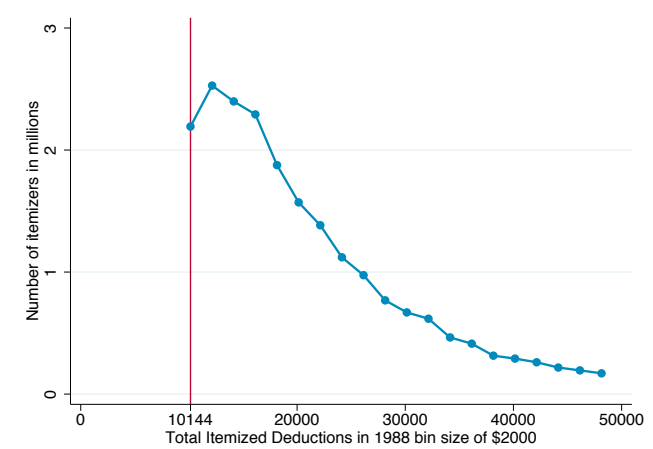

(c) 1988

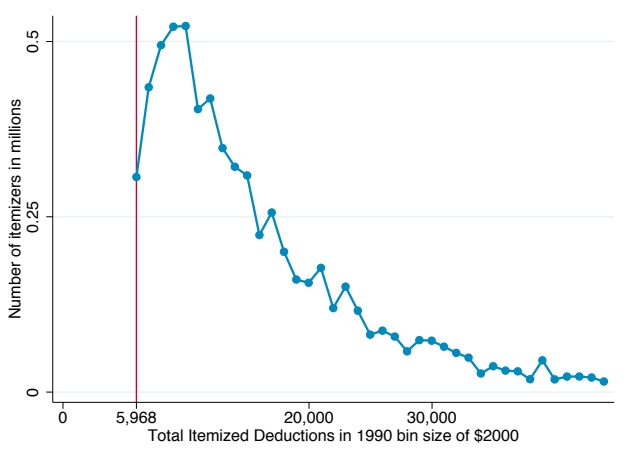

(e) 1990

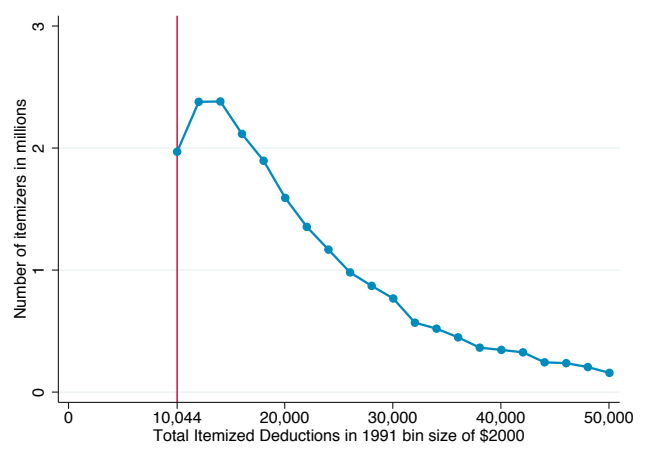

(f) 1991

Notes: The figures above plot the density of deductions for itemizers filing jointly. The bin size is $\$ 2,000$ and the vertical line represents the standard deduction threshold for each year. 
Figure H.14: Missing Mass Just Above the Standard Deduction 1980-1985 (Joint Filers)

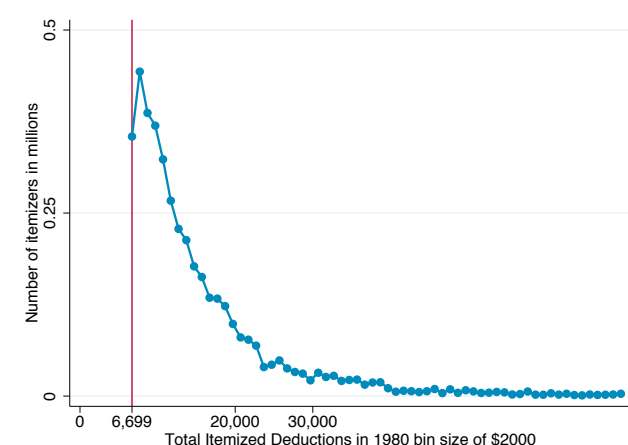

(a) 1980

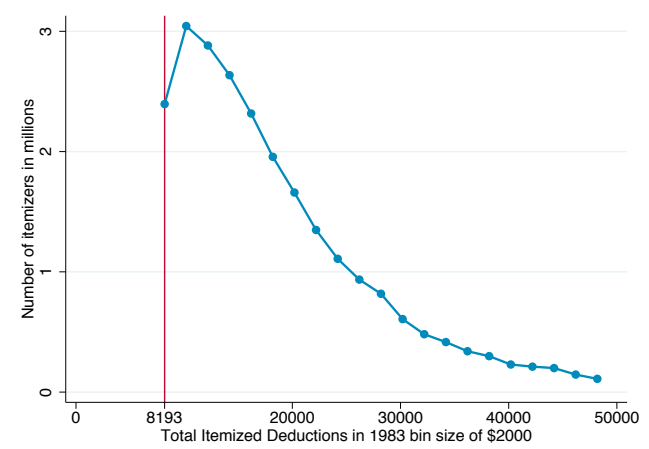

(d) 1983

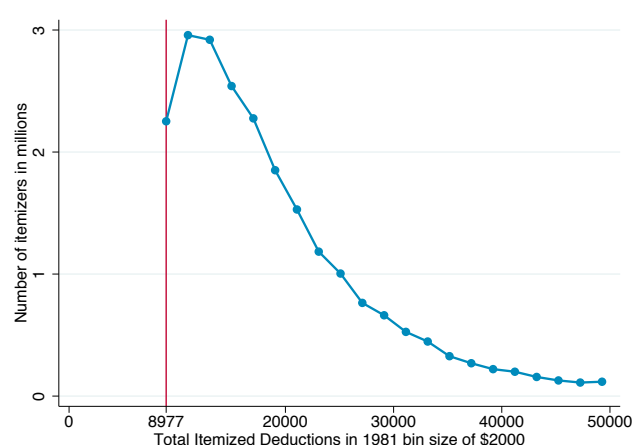

(b) 1981

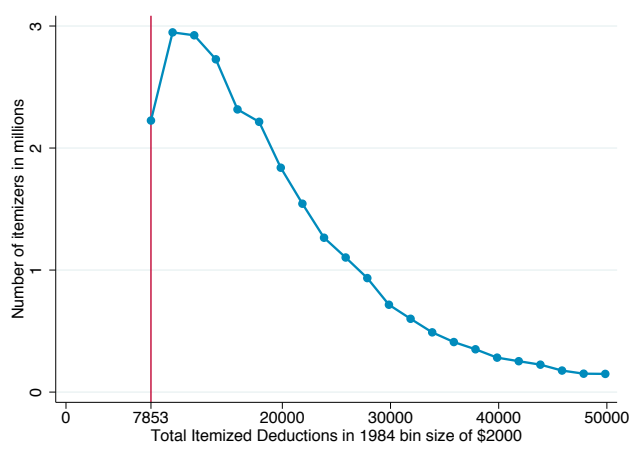

(e) 1984

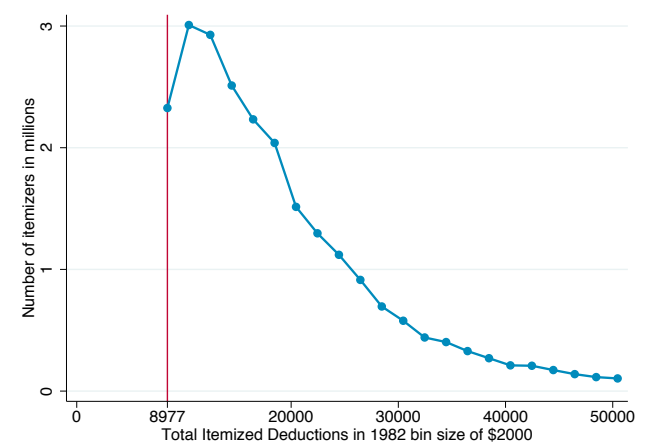

(c) 1982

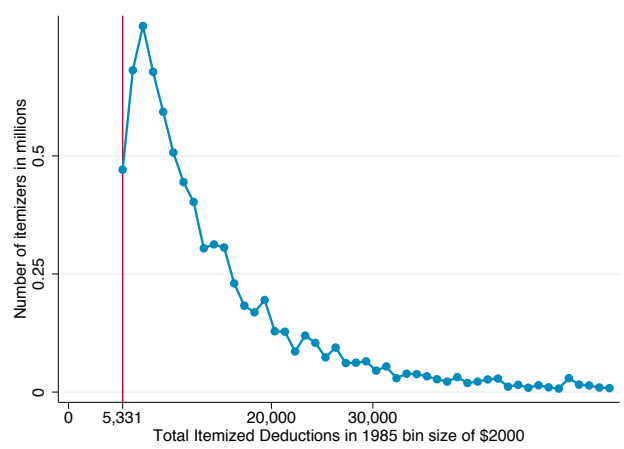

(f) 1985

Notes: The figures above plot the density of deductions for itemizers filing jointly. The bin size is $\$ 2,000$ and the vertical line represents the standard deduction threshold for each year. 
Figure H.15: Missing Mass Just Above the Standard Deduction (Single Filers)

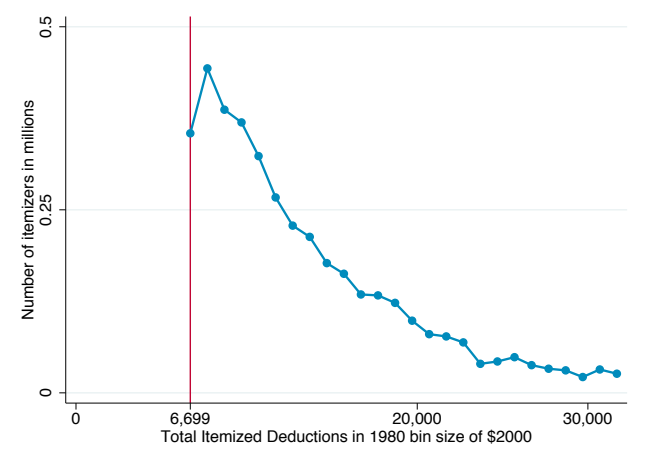

(a) 1980

兒

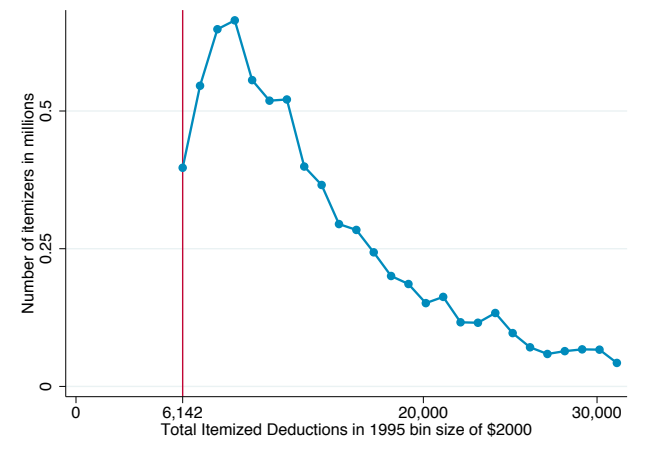

(d) 1995

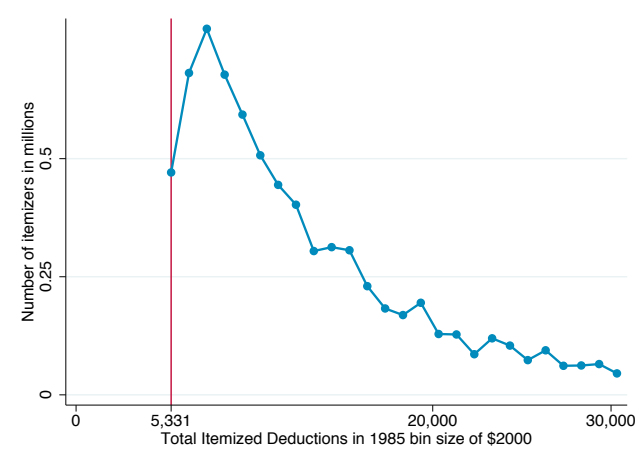

(b) 1985

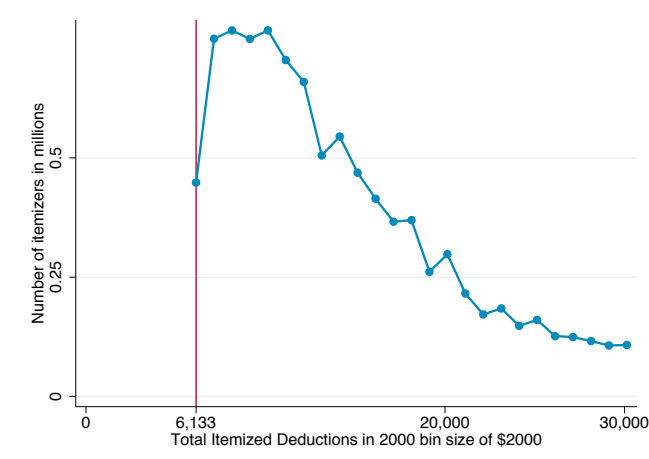

(e) 2000

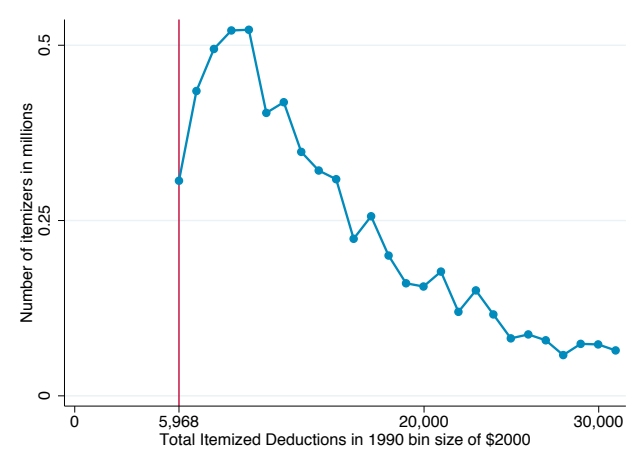

(c) 1990

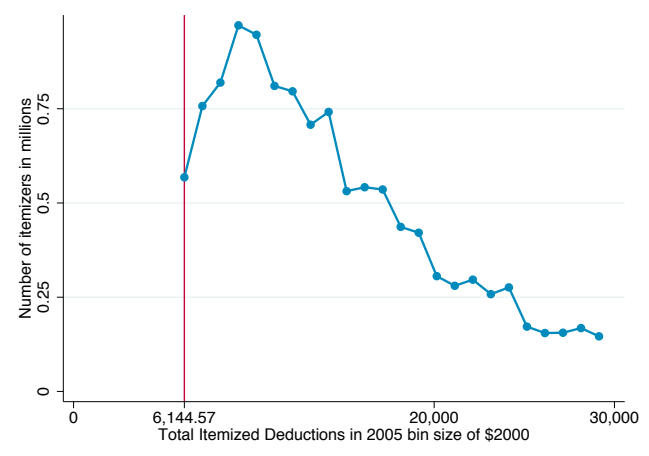

(f) 2005

Notes: The figures above plot the density of deductions for single filers who itemize deductions. The bin size is $\$ 2,000$ and the vertical line represents the standard deduction threshold for each year. 


\section{Figure H.16: Reduced Form Evidence of the Existence of Compliance Costs}

(a) 1970-1971 Comparison

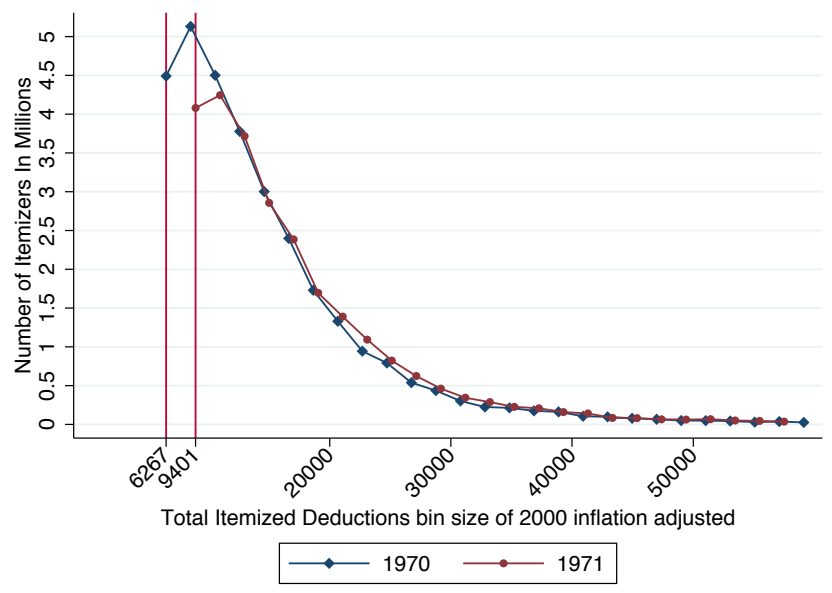

(b) 1974-1975 Comparison

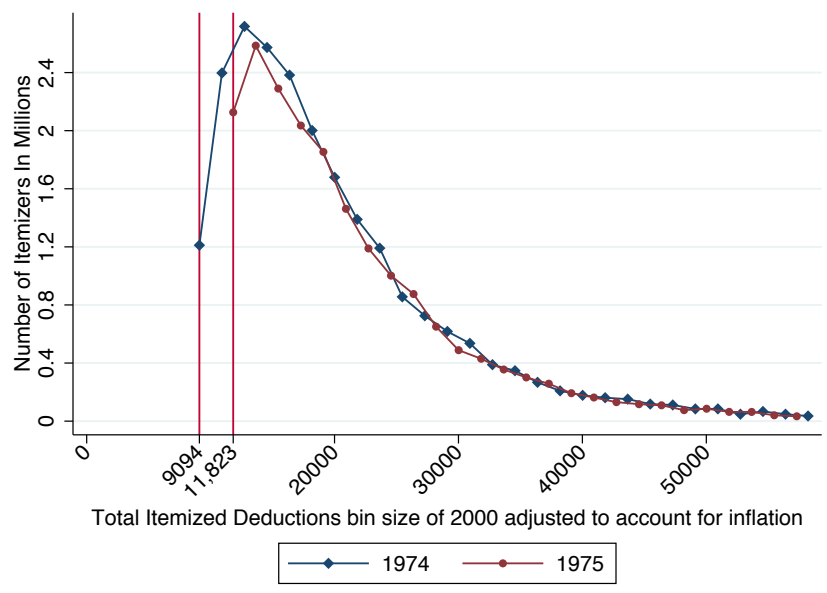

(c) 2002-2003 Comparison

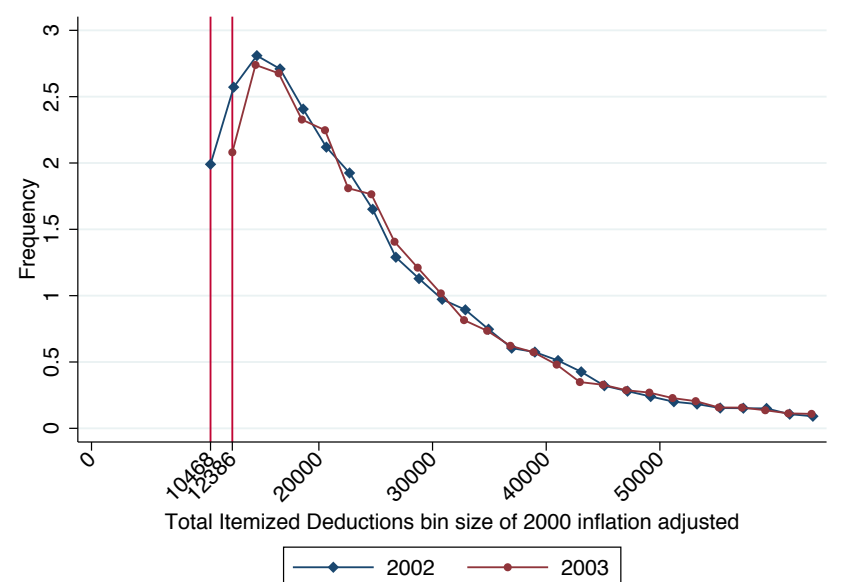

Notes: These graph plot the density of deductions before and at the time of the 1971, 1975 and 2003 reforms. While these show reduced form evidence of the existence of compliance costs, they do not provide accurate estimates of these compliance costs because other changes occurred at the same time. 


\section{Figure H.17: Placebo Test: Overlapping Densities In Years With No Reforms}

(a) 1990-1992

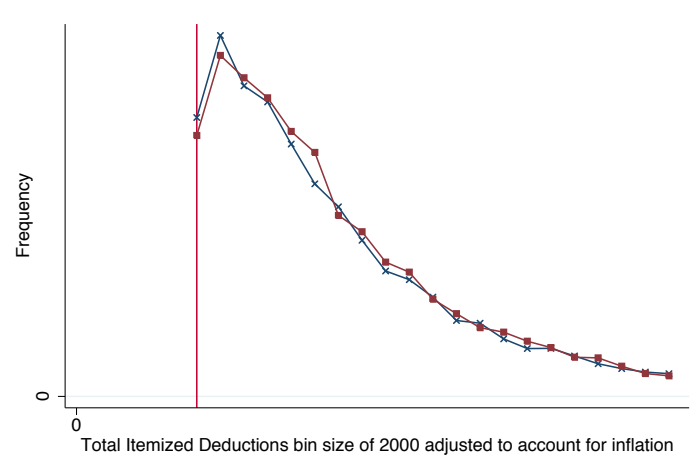

(c) $1992-1994$

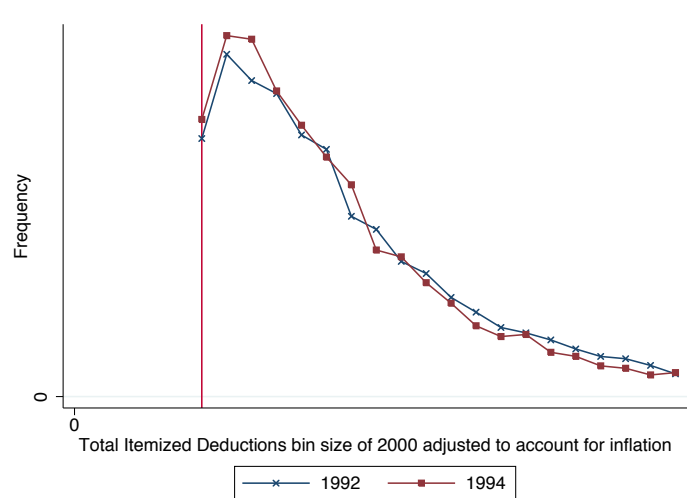

(b) 1991-1993

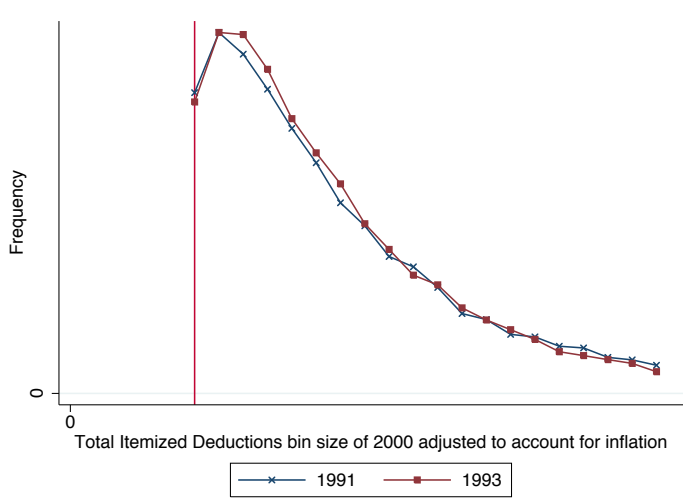

(d) 1993-1995

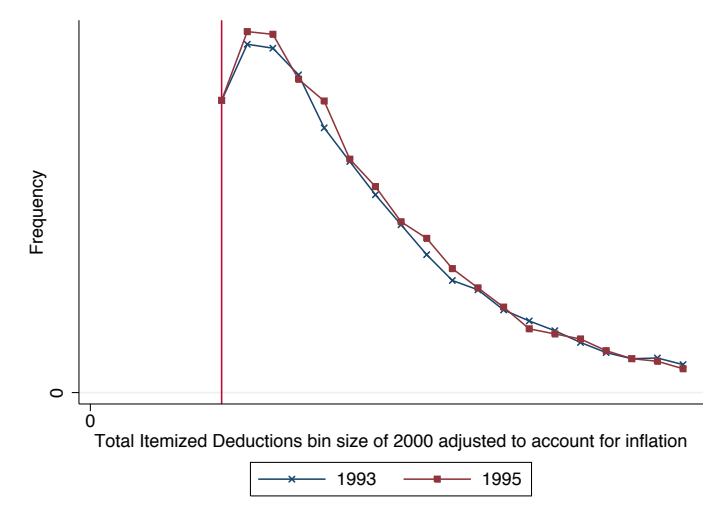

Notes: The figures above test assumption A1 which states the cost of itemizing does not vary from year to year. 


\section{Figure H.18: Placebo Test: Overlapping Densities In Years With No Reforms}

(a) 1994-1996

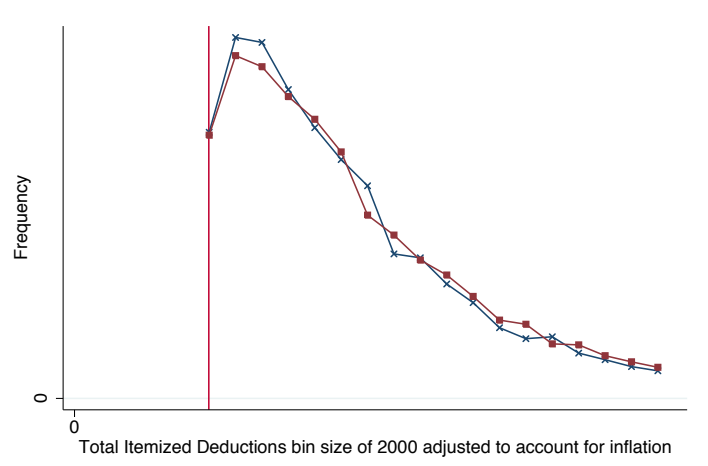

(c) 1996-1998

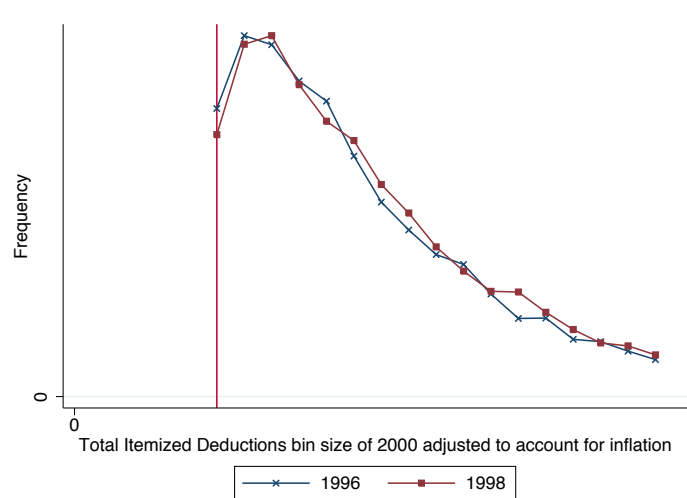

(b) 1995-1997

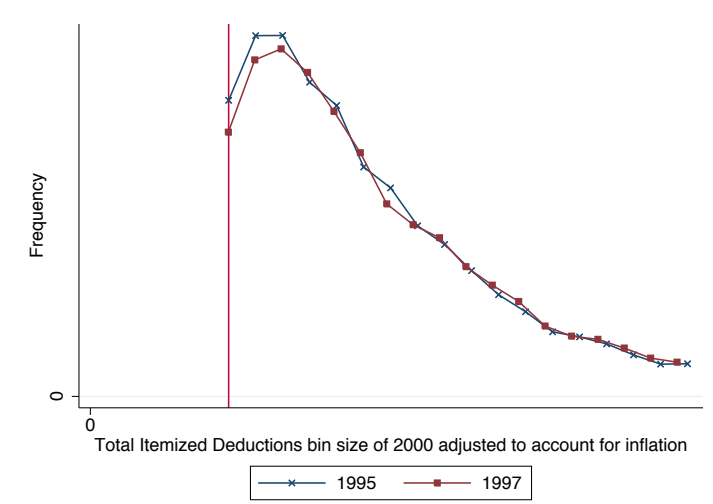

(d) 1997-1999

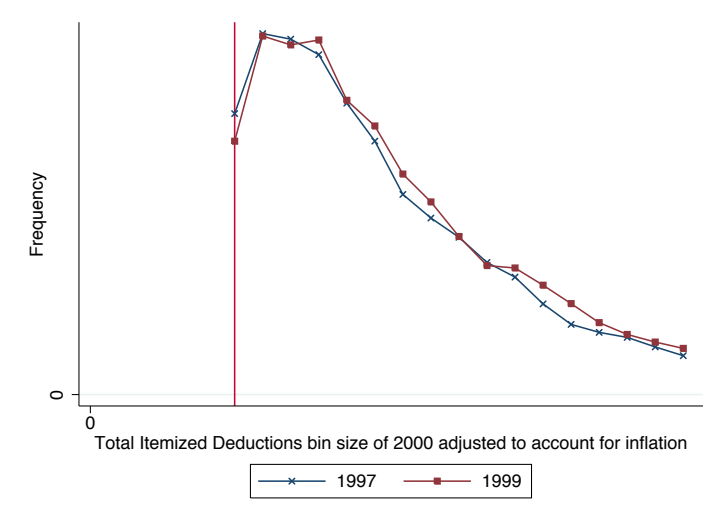

Notes: The figures above test assumption A1 which states the cost of itemizing does not vary from year to year. 


\section{Figure H.19: Placebo Test: Overlapping Densities In Years With No Reforms}

(a) $1998-2000$

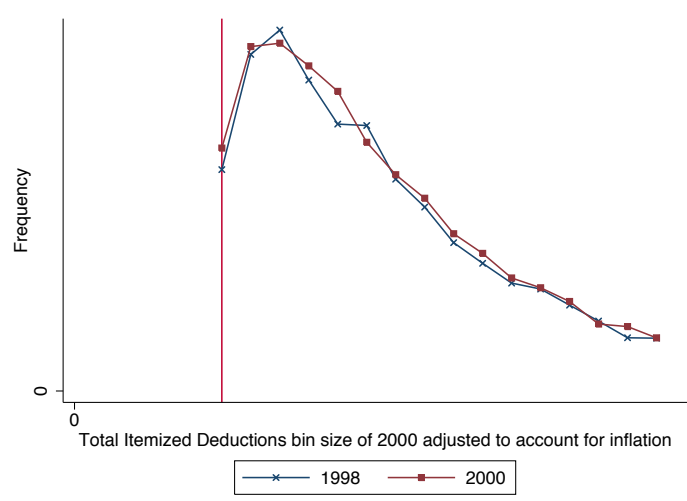

(b) 1999-2001

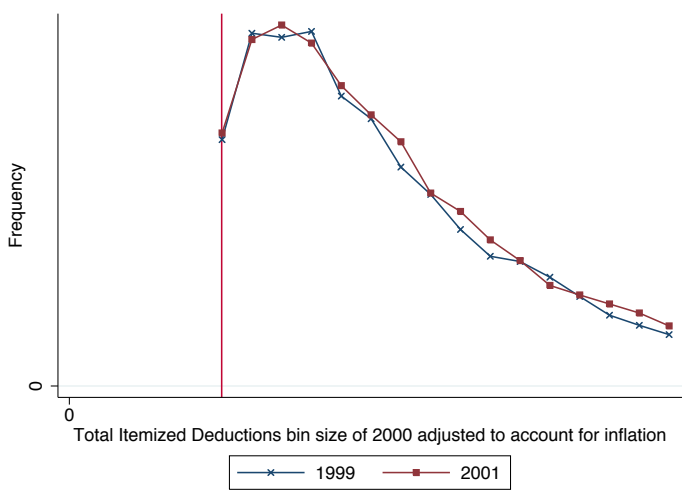

Notes: The figures above test assumption A1 which states the cost of itemizing does not vary from year to year. 


\section{Figure H.20: Effect of Electronic Filing on Cost}

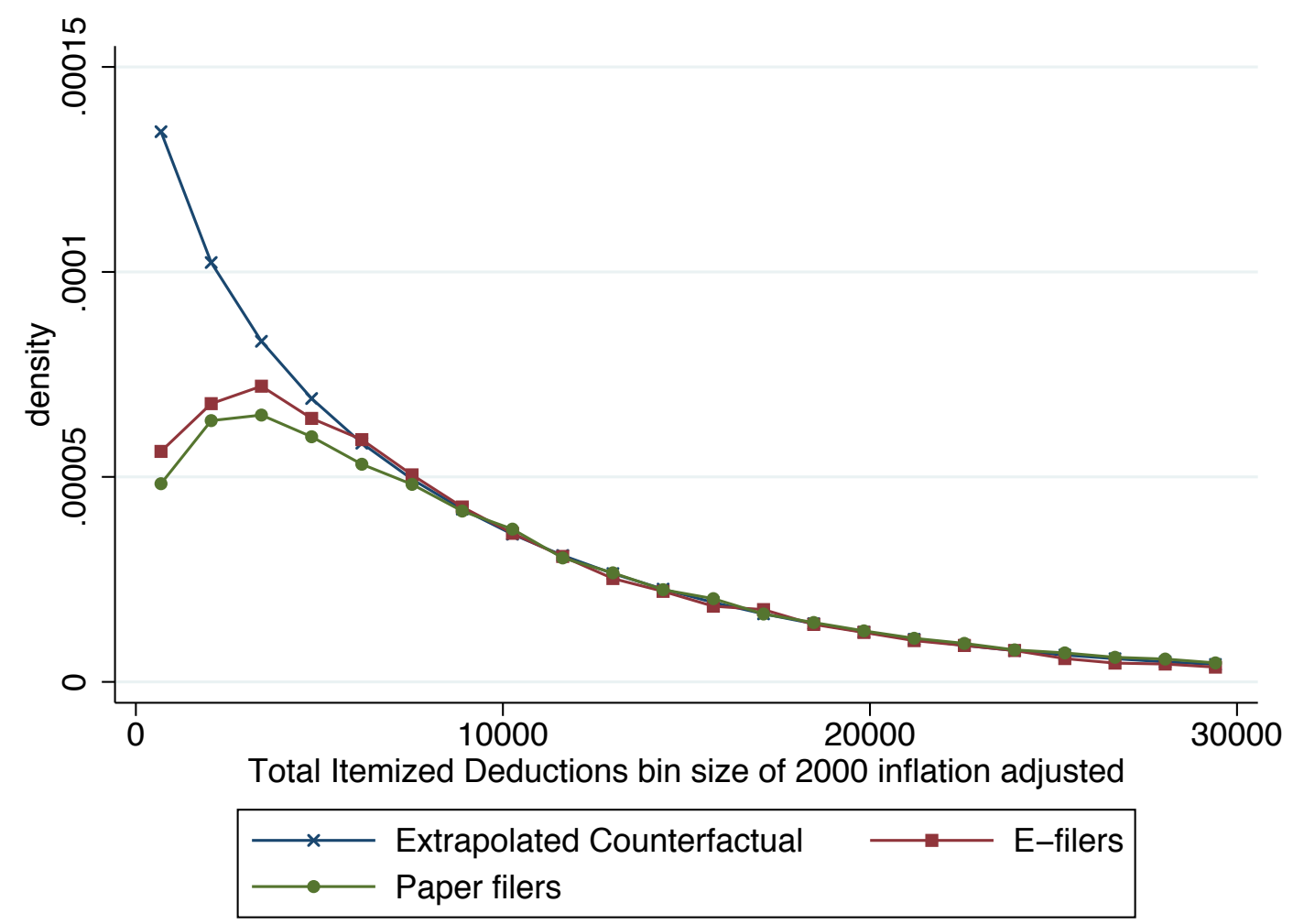

Notes: This graph pools all cross sections from 1998 to 2006 for joint filers and plots the distribution of itemizers using electronic filing and paper filing. It uses the area away from the standard deduction to extrapolate the shape of the counterfactual distribution of itemizers just above the standard deduction. 


\section{Figure H.21: Forgone Benefits Increase With Income}

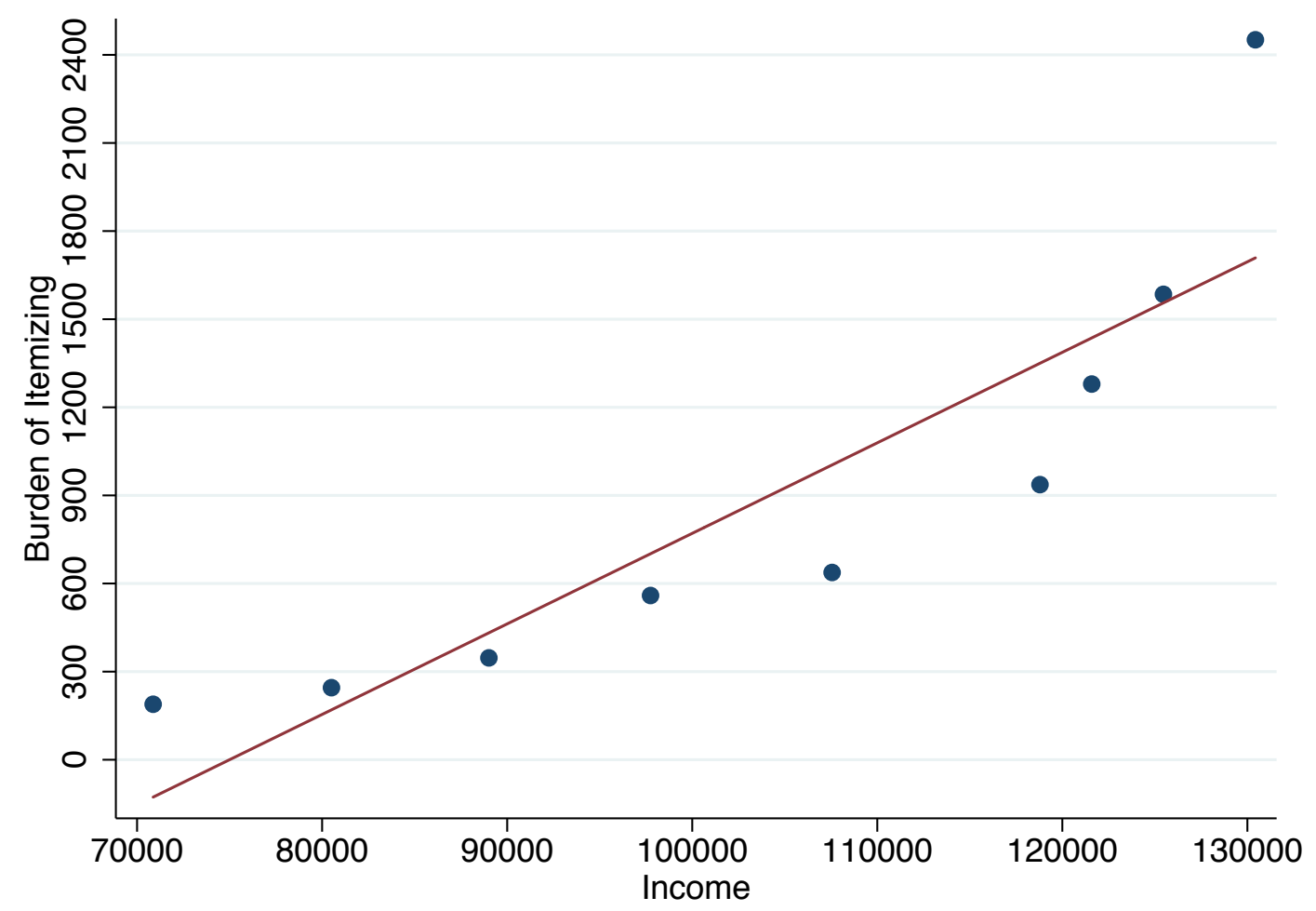

Notes: This graph plots the relationship between forgone benefits and income for all income deciles. 


\section{Figure H.22: Different Scenarios Below the Standard Deduction}

(a) Increasing: Impossible

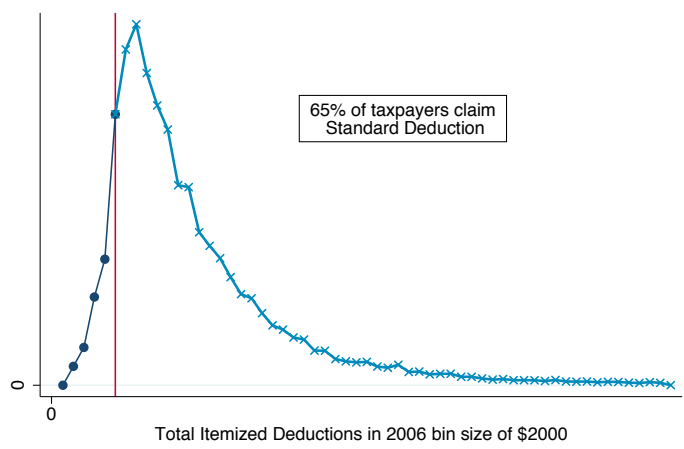

(b) Double Peaked: Unlikely

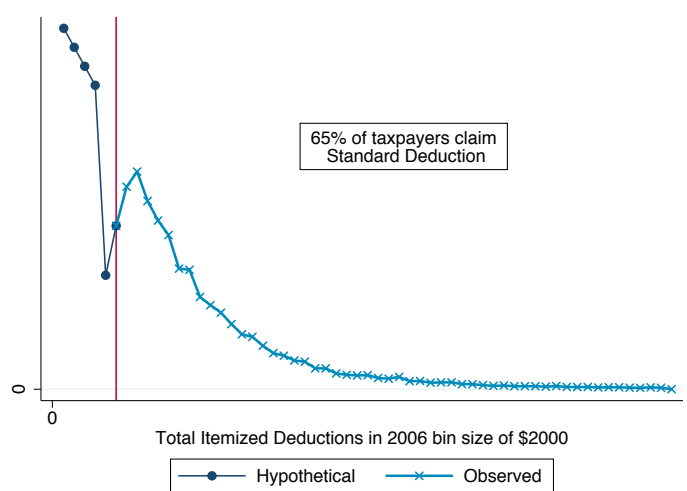

(c) Missing Mass

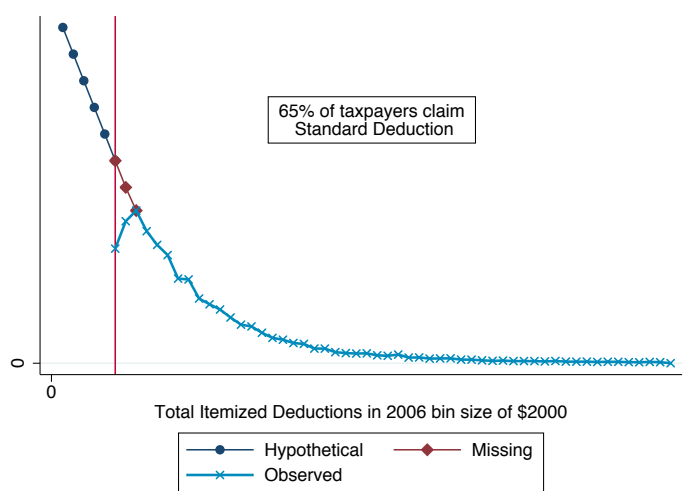

Notes: The graphs above plot the different scenarios that could be happening below the standard deduction. Graph (a) assumes that the density is strictly increasing, which is impossible given that $65 \%$ of taxpayers claim the standard deduction. This scenario would fail to account for most of the population of taxpayers. Graph (b) accounts for most of the population and is continuous at the standard deduction but the density is double peaked. This is possible but unlikely given that densities are usually single peaked. This however does not rule out densities that are double-peaked because of the standard deduction. Graph (c) assumes that there is a discontinuity at the standard deduction threshold because of compliance costs creating a missing mass. 
Figure H.23: No Behavioral Response For Personal Interest Deduction

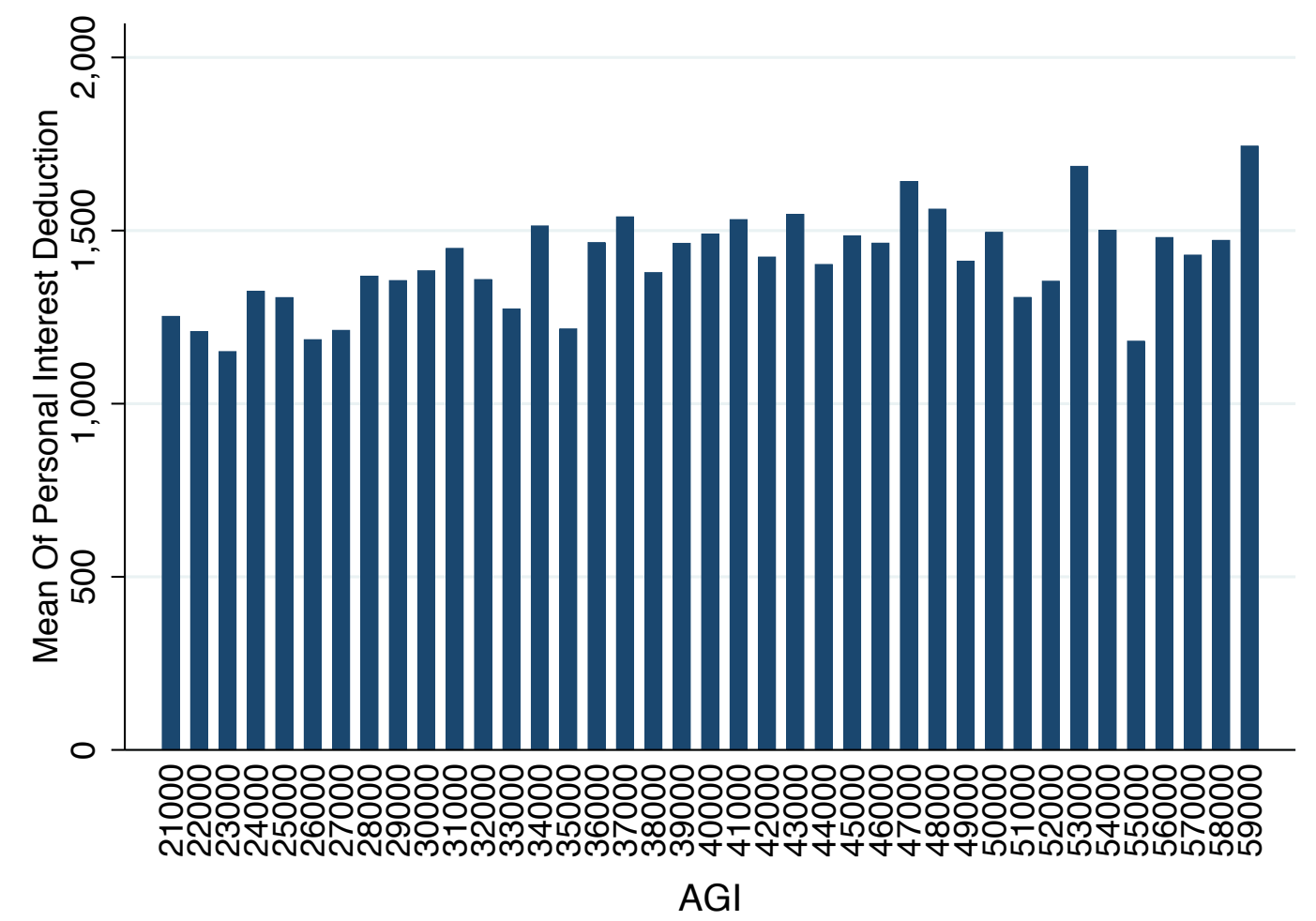

Notes: This figure plots the average personal interest deduction claimed by income bins of $\$ 1000$ in 1989 . Below $\$ 30,950$, the marginal tax rate is $15 \%$ for married filing jointly and above it is equal to $28 \%$. If taxpayers were responding to tax incentives when claiming the personal interest deduction, one would observe a discontinuity at the MTR threshold. None is observed here. 


\section{APPENDIX TABLES}

\section{Table I.4: Standard Deduction By Year For Joint Filers}

\begin{tabular}{|c|c|c|c|c|c|c|c|}
\hline Year & $\begin{array}{l}\text { Standard } \\
\text { deduction }\end{array}$ & $\begin{array}{c}\text { S.D. } \\
\text { in } 2014 \$\end{array}$ & $\begin{array}{c}\text { Growth } \\
\text { Rate }\end{array}$ & $\overline{\text { Year }}$ & $\begin{array}{l}\text { Standard } \\
\text { deduction }\end{array}$ & $\begin{array}{c}\text { S.D. } \\
\text { in } 2014 \$\end{array}$ & $\begin{array}{c}\text { Growth } \\
\text { Rate }\end{array}$ \\
\hline 1961 & 1000 & 7968 & $0.00 \%$ & 1984 & 3400 & 7796 & $0.00 \%$ \\
\hline 1962 & 1000 & 7889 & $0.00 \%$ & 1985 & 3540 & 7838 & $4.12 \%$ \\
\hline 1963 & 1000 & 7786 & $0.00 \%$ & 1986 & 3670 & 7978 & $3.67 \%$ \\
\hline 1964 & 1000 & 7686 & $0.00 \%$ & 1987 & 3760 & 7886 & $2.45 \%$ \\
\hline 1965 & 1000 & 7564 & $0.00 \%$ & 1988 & 5000 & 10070 & $32.98 \%$ \\
\hline 1966 & 1000 & 7353 & $0.00 \%$ & 1989 & 5200 & 9991 & $4.00 \%$ \\
\hline 1967 & 1000 & 7133 & $0.00 \%$ & 1990 & 5450 & 9935 & $4.81 \%$ \\
\hline 1968 & 1000 & 6846 & $0.00 \%$ & 1991 & 5700 & 9971 & $4.59 \%$ \\
\hline 1969 & 1000 & 6492 & $0.00 \%$ & 1992 & 6000 & 10189 & $5.26 \%$ \\
\hline 1970 & 1000 & 6140 & $0.00 \%$ & 1993 & 6200 & 10223 & $3.33 \%$ \\
\hline 1971 & 1500 & 8824 & $50.00 \%$ & 1994 & 6350 & 10208 & $2.42 \%$ \\
\hline 1972 & 2000 & 11400 & $33.33 \%$ & 1995 & 6550 & 10240 & $3.15 \%$ \\
\hline 1973 & 2000 & 10732 & $0.00 \%$ & 1996 & 6700 & 10174 & $2.29 \%$ \\
\hline 1974 & 2000 & 9665 & $0.00 \%$ & 1997 & 6900 & 10243 & $2.99 \%$ \\
\hline 1975 & 2600 & 11514 & $30.00 \%$ & 1998 & 7100 & 10378 & $2.90 \%$ \\
\hline 1976 & 2800 & 11724 & $0.08 \%$ & 1999 & 7200 & 10293 & $1.41 \%$ \\
\hline 1977 & 3200 & 12580 & $0.14 \%$ & 2000 & 7350 & 10169 & $2.08 \%$ \\
\hline 1978 & 3200 & 11693 & $0.00 \%$ & 2001 & 7600 & 10515 & $3.40 \%$ \\
\hline 1979 & 3400 & 11158 & $0.06 \%$ & 2002 & 7850 & 10560 & $3.29 \%$ \\
\hline 1980 & 3400 & 9831 & $0.00 \%$ & 2003 & 9500 & 12301 & $21.02 \%$ \\
\hline 1981 & 3400 & 8911 & $0.00 \%$ & 2004 & 9700 & 12234 & $2.11 \%$ \\
\hline 1982 & 3400 & 8394 & $0.00 \%$ & 2005 & 10000 & 12199 & $3.09 \%$ \\
\hline 1983 & 3400 & 8133 & $0.00 \%$ & 2006 & 10300 & 12173 & $3.00 \%$ \\
\hline
\end{tabular}

Notes: The table shows the standard deduction amounts from 1961 to 2006 for joint filers and its growth rate. The years that I use to identify the cost of itemizing deductions are in bold. 
Table I.5: Standard Errors of the Difference Between the 1970 and 1971 Densities (figure H.16a)

\begin{tabular}{ccccc}
\hline \hline Bin & $\begin{array}{c}\text { Deduction } \\
\text { Range }\end{array}$ & Difference & $\begin{array}{c}\text { Standard } \\
\text { Errors }\end{array}$ & Z-stat \\
\hline 1 & {$[6140,9140]$} & $0.00373^{* * *}$ & 0.00102 & 3.64 \\
2 & $(9140,12140]$ & $0.00288^{* * *}$ & 0.00090 & 3.20 \\
3 & $(12140,15140]$ & $0.00307^{* * *}$ & 0.00074 & 4.11 \\
4 & $(15140,18140]$ & $0.00083^{*}$ & 0.00046 & 1.81 \\
5 & $(18140,21140]$ & 0.00019 & 0.00037 & 0.54 \\
6 & $(21140,24140]$ & 0.00039 & 0.00027 & 1.45 \\
7 & $(24140,27140]$ & -0.00025 & 0.00018 & -1.41 \\
8 & $(27140,30140]$ & -0.00001 & 0.00015 & -0.09 \\
9 & $(30140,33140]$ & -0.00007 & 0.00011 & -0.63 \\
10 & $(33140,36140]$ & -0.00010 & 0.00010 & -0.94 \\
\hline \hline
\end{tabular}

Notes: This table shows the bootstrapped standard errors for the difference between bins in 1970 and 1971 for taxpayers with deductions below $\$ 30,000 . *$ denotes significance at the $10 \%$ level, ${ }^{* *}$ at the $5 \%$ level and ${ }^{* * *}$ at the $1 \%$ level. I use 100 replications for the bootstrap estimation. 
Table I.6: Standard Errors of the Difference Between the Density of Electronic Filers v.s. Paper Filers (Figure 5(b))

\begin{tabular}{ccccc}
\hline \hline Bin & $\begin{array}{c}\text { Deduction } \\
\text { Range }\end{array}$ & Difference & $\begin{array}{c}\text { Standard } \\
\text { Errors }\end{array}$ & z-stat \\
\hline 1 & {$[0,2000)$} & $7.08 \mathrm{e}-06^{* * *}$ & $1.44 \mathrm{e}-06$ & 4.92 \\
2 & {$[2000,4000)$} & $3.02 \mathrm{e}-06^{*}$ & $1.55 \mathrm{e}-06$ & 1.95 \\
3 & {$[4000,6000)$} & $5.91 \mathrm{e}-06^{* * *}$ & $1.39 \mathrm{e}-06$ & 4.25 \\
4 & {$[6000,8000)$} & $3.44 \mathrm{e}-06^{* *}$ & $1.54 \mathrm{e}-06$ & 2.23 \\
5 & {$[8000,10000)$} & $5.10 \mathrm{e}-06^{* * *}$ & $1.49 \mathrm{e}-06$ & 3.42 \\
6 & {$[10000,12000)$} & $1.47 \mathrm{e}-06$ & $1.41 \mathrm{e}-06$ & 1.04 \\
7 & {$[12000,14000)$} & $2.37 \mathrm{e}-07$ & $1.42 \mathrm{e}-06$ & 0.17 \\
8 & {$[14000,16000)$} & $-1.73 \mathrm{e}-06$ & $1.18 \mathrm{e}-06$ & -1.47 \\
9 & {$[16000,18000)$} & $-1.93 \mathrm{e}-07$ & $1.04 \mathrm{e}-06$ & -0.19 \\
10 & {$[20000,22000)$} & $-1.88 \mathrm{e}-06^{*}$ & $1.03 \mathrm{e}-06$ & -1.82 \\
\hline \hline
\end{tabular}

Table I.7: Standard Errors of the Difference Between the Density of March vs. April Filers (Figure 8c)

\begin{tabular}{ccccc}
\hline \hline Bin & $\begin{array}{c}\text { Deduction } \\
\text { Range }\end{array}$ & Difference & $\begin{array}{c}\text { Standard } \\
\text { Errors }\end{array}$ & z-stat \\
\hline 1 & {$[0,2000)$} & $-.000012^{* * *}$ & $2.87 \mathrm{e}-06$ & -4.17 \\
2 & {$[2000,4000)$} & $-.0000114^{* * *}$ & $2.83 \mathrm{e}-06$ & -4.02 \\
3 & {$[4000,6000)$} & $-5.08 \mathrm{e}-06$ & $3.09 \mathrm{e}-06$ & -1.64 \\
4 & {$[6000,8000)$} & $-.0000141^{* * *}$ & $3.39 \mathrm{e}-06$ & -4.17 \\
5 & {$[8000,10000)$} & $-9.22 \mathrm{e}-06^{* * *}$ & $3.41 \mathrm{e}-06$ & -2.71 \\
6 & {$[10000,12000)$} & $-8.12 \mathrm{e}-06^{* *}$ & $3.42 \mathrm{e}-06$ & -2.51 \\
7 & {$[12000,14000)$} & $-4.21 \mathrm{e}-06$ & $1.42 \mathrm{e}-06$ & -1.23 \\
8 & {$[14000,16000)$} & $-5.94 \mathrm{e}-06$ & $3.05 \mathrm{e}-06$ & -1.94 \\
9 & {$[16000,18000)$} & $-4.86 \mathrm{e}-07^{*}$ & $3.36 \mathrm{e}-06$ & -0.14 \\
10 & {$[20000,22000)$} & $-5.57 \mathrm{e}-06^{* *}$ & $2.81 \mathrm{e}-06$ & -1.98 \\
\hline \hline
\end{tabular}

Notes: These two tables show the bootstrapped standard errors for the difference between the density of itemizers who use electronic filing versus paper filing in the first table and the difference between April and March Filers in the second table.

${ }^{*}$ denotes significance at the $10 \%$ level, ${ }^{* *}$ at the $5 \%$ level and ${ }^{* * *}$ at the $1 \%$ level. 
Table I.8: Survey Based Estimates of the Compliance Costs of Taxation in the US

\begin{tabular}{|c|c|c|c|}
\hline Article & Methodology & $\begin{array}{c}\text { Cost of } \\
\text { Itemizing Deductions }\end{array}$ & $\begin{array}{l}\text { Aggregate Costs } \\
\text { of Filing Taxes }\end{array}$ \\
\hline $\begin{array}{c}\text { Wicks (1965) and } \\
\text { Wicks and Killworth (1967) }\end{array}$ & $\begin{array}{l}\text { Survey of Montana } \\
\text { residents }\end{array}$ & Not reported & $\begin{array}{l}32 \% \text { of state and } 11.5 \% \\
\text { of federal tax revenue }\end{array}$ \\
\hline Slemrod and Sorum (1984) & $\begin{array}{c}\text { Survey of } 2000 \\
\text { Minnesota residents }\end{array}$ & Not reported & $\begin{array}{c}5 \% \text { to } 7 \% \text { of } \\
\text { total tax revenue } \\
\end{array}$ \\
\hline $\begin{array}{c}\text { Little (1988), } \\
\text { Commissionned by IRS }\end{array}$ & $\begin{array}{l}\text { Two separate surveys of } \\
750 \text { and } 6200 \text { taxpayers }\end{array}$ & Not reported & $\begin{array}{c}1.59 \text { billion } \\
\text { hours } \\
\end{array}$ \\
\hline Slemrod (1989) & $\begin{array}{l}\text { Estimate structural model based on } \\
\text { survey of } 2000 \text { Minnesota residents }\end{array}$ & 3.2 to 3.5 hours & Not reported \\
\hline Blumenthal and Slemrod (1992) & $\begin{array}{c}\text { Survey of } 2000 \text { Minnesota } \\
\text { households in } 1990\end{array}$ & 9 hours & $\begin{array}{l}85 \text { billion } \\
\text { dollars }\end{array}$ \\
\hline Guyton et al. (2003) & $\begin{array}{c}\text { Survey and ITBM* } \\
\text { simulations }\end{array}$ & 9.9 hours & $\begin{array}{l}18.7 \text { billion hours } \\
\text { dollars }\end{array}$ \\
\hline
\end{tabular}

Notes: This table reports the results of several research article documenting the cost of tax filing using survey evidence. ${ }^{*}$ ITBM stands for the Individual Tax Burden Model. 
Table I.9: Articles Documenting Low Take-Up Rates/Large Forgone Benefits

\begin{tabular}{ccc}
\hline \hline Article & Setting & Forgone Benefits \\
\hline \hline Steuerle et al. (1978) & Tax Benefits/Income Averaging & $\$ 666$ \\
\hline Blank and Card (1991) & Unemployment Insurance Benefits & $\begin{array}{c}\text { Take-up rate of less than 30\% } \\
\text { of eligible unemployed individuals }\end{array}$ \\
\hline Madrian and Shea (2001) & Retirement Savings & $\begin{array}{c}50 \% \text { match of retirement savings } \\
\text { up to 6\% of contributions }\end{array}$ \\
\hline Sydnor (2010) & Home Insurance & Five times the insurance premium \\
\hline Bhargava and Manoli (2015) & Taxes & $\begin{array}{c}\text { Earned Income } \\
\text { Tax Credit Benefits }\end{array}$ \\
\hline Handel (2013) & Health Insurance & $\$ 2,032$ per year \\
\hline \hline Keys et al. (2014) & Mortgage Refinancing & Present discounted cost of $\$ 11,500$ \\
\hline
\end{tabular}




\section{Table I.10: IRS Hourly Cost Estimates}

\begin{tabular}{|c|c|c|c|c|c|}
\hline Form & Recordkeeping & $\begin{array}{l}\text { Learning about the } \\
\text { law or the form }\end{array}$ & $\begin{array}{l}\text { Preparing } \\
\text { the form }\end{array}$ & $\begin{array}{l}\text { Copying, assembling } \\
\text { and sending the form } \\
\text { to the IRS }\end{array}$ & Total \\
\hline $\begin{array}{c}1040 \\
\text { Sch. A } \\
\text { Sch. B } \\
\text { Sch. C } \\
\text { Sch. D } \\
\text { Sch. D-1 } \\
\text { Sch. E } \\
\text { Sch. F } \\
\text { Sch. R } \\
\text { Sch. SE short } \\
\text { Sch. SE long }\end{array}$ & 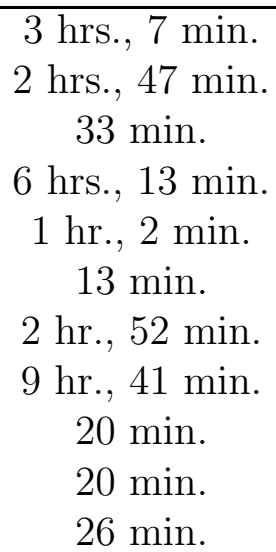 & $\begin{array}{l}2 \mathrm{hrs.}, 32 \mathrm{~min} . \\
26 \mathrm{~min} . \\
8 \mathrm{~min} . \\
1 \mathrm{hr} ., 4 \mathrm{~min} . \\
1 \mathrm{hr} . \\
1 \mathrm{~min} . \\
1 \mathrm{hr} ., 7 \mathrm{~min} . \\
1 \mathrm{hr} ., 59 \mathrm{~min} . \\
15 \mathrm{~min} . \\
11 \mathrm{~min} . \\
22 \mathrm{~min} .\end{array}$ & $\begin{array}{l}3 \mathrm{hrs.}, 10 \mathrm{~min} . \\
1 \mathrm{hr} ., 1 \mathrm{~min} . \\
16 \mathrm{~min} . \\
1 \mathrm{hr} ., 56 \mathrm{~min} . \\
1 \mathrm{hr} ., 8 \mathrm{~min} . \\
13 \mathrm{~min} . \\
1 \mathrm{hr} ., 16 \mathrm{~min} . \\
3 \mathrm{hr} ., 52 \mathrm{~min} . \\
22 \mathrm{~min} . \\
13 \mathrm{~min} . \\
37 \mathrm{~min} .\end{array}$ & $\begin{array}{l}35 \mathrm{~min} . \\
20 \mathrm{~min} . \\
20 \mathrm{~min} . \\
25 \mathrm{~min} . \\
35 \mathrm{~min} . \\
35 \mathrm{~min} . \\
35 \mathrm{~min} . \\
35 \mathrm{~min} . \\
35 \mathrm{~min} . \\
14 \mathrm{~min} . \\
20 \mathrm{~min} .\end{array}$ & $\begin{array}{l}9 \mathrm{hrs} ., 24 \mathrm{~min} . \\
4 \mathrm{hrs} ., 34 \mathrm{~min} . \\
1 \mathrm{hr} ., 17 \mathrm{~min} . \\
9 \mathrm{hrs}, 38 \mathrm{~min} . \\
3 \mathrm{hrs.}, 45 \mathrm{~min} . \\
1 \mathrm{hr} ., 2 \mathrm{~min} . \\
5 \mathrm{hrs}, 50 \mathrm{~min} . \\
16 \mathrm{hrs} ., 7 \mathrm{~min} . \\
1 \mathrm{hr} ., 32 \mathrm{~min} . \\
58 \mathrm{~min} . \\
1 \mathrm{hr} ., 45 \mathrm{~min} .\end{array}$ \\
\hline
\end{tabular}

Notes: Each cell of this table is an estimate of the time it takes to perform each task associated with each tax schedule. They are based on IRS surveys of taxpayers at the time of filing and are reported in the 1040 instructions (on page 3 in 1989). There is no information on Sch. R in the SOI public use files so its cost is not estimated in this paper. 